www.nature.com/pj

\title{
Recent developments in metal-catalyzed living radical polymerization
}

\author{
Masami Kamigaito
}

This review presents a short overview of recent developments in metal-catalyzed living radical polymerization, mainly focusing on our recent research studies related to the subject. Metal-catalyzed living radical polymerization or atom transfer radical polymerization, which was originally developed via evolution of the metal-catalyzed Kharasch or atom transfer radical addition to chain-growth polymerization via reversible activation, has now been widely developed in many aspects. The effective metal catalysts include various transition metals, such as ruthenium, copper, iron and nickel, and highly active and versatile catalytic systems have been developed by designing ligands, applying lower oxidation metal species and using additives to widen the scope of controllable monomers and to minimize the amount of metal catalysts and the residual metals in the products. The development of the initiating systems has enabled the synthesis of a wide variety of novel, well-defined polymers, including end-functionalized, block, graft and star polymers, but also more complicated polymers possessing multiple controlled structures. Furthermore, metal-catalyzed living radical polymerization has been judiciously combined with stereospecific radical polymerization based on the use of polar solvents or Lewis acid additives, resulting in the dual control of the molecular weight and the tacticity of the resulting polymers and enabling the preparation of stereoblock and stereogradient polymers.

Polymer Journal (2011) 43, 105-120; doi:10.1038/pj.2010.113; published online 17 November 2010

Keywords: block polymer; living radical polymerization; precision polymer synthesis; transition metal catalyst; star polymer; stereospecific polymerization

\section{INTRODUCTION}

Since the discovery of metal-catalyzed living radical polymerization or atom transfer radical polymerization (ATRP), there have been many developments in this research area, including active and versatile metal catalytic systems; the scope of controllable monomers; well-defined polymers with various controlled architectures; hybridization of the controlled polymers with inorganic, metal and biomolecular compounds; and attempts or real applications to a variety of industrial materials. ${ }^{1-17}$ Besides these metal catalytic systems, there have also been substantial developments in various living radical polymerizations, such as nitroxide-mediated polymerizations, reversible addition fragmentation chain-transfer polymerizations and others, and in all of these, there are characteristic features of the mechanisms and components. ${ }^{18-34}$

The metal-catalyzed living radical polymerization was originally discovered via evolution of the metal-catalyzed Kharasch or atom transfer radical addition reaction ${ }^{35}$ to the chain-growth polymerization of vinyl monomers (Figure 1). ${ }^{1}$ The initiating system generally consists of a transition metal complex in a lower oxidation state and an organic halide, in which the carbon-halogen bond of the halogen compound is activated by the metal catalyst to generate the carbon radical species upon a one-electron oxidation of the metal complex associated with the abstraction of the halogen by the metal species.
The carbon radical species generated then adds to the monomer to generate the adduct radical, which is eventually capped with the halogen on the higher oxidation state metal complex or may add to another monomer molecule. The halogen-capping reaction of the radical species occurs faster than monomer addition and slows the very fast propagation of a particular growing radical chain end to suppress the formation of very long polymer chains, particularly during the initial stage of the polymerization. Furthermore, the newly formed carbon-halogen bond of the adduct or at the oligomeror polymer-chain end can be activated again by the metal catalyst to reversibly generate the growing radical species. Herein, the covalent species with the carbon-halogen terminal is called the 'dormant' species as in the other living anionic and cationic polymerizations via similarly reversible, but heterolytic activation of the covalent terminal group into the active species. ${ }^{36,37}$ Such a metal-catalyzed reversible activation of the carbon-halogen terminal gives an almost equal opportunity of propagation to each polymer chain to enable control of the chain length of the resulting polymer chains. In addition, the equilibrium between the radical and dormant species can diminish the radical concentration, which contributes to the suppression of the bimolecular termination between the growing radical species. A wide variety of transition metals have now been used as effective catalysts in the presence of the appropriate ligands. 


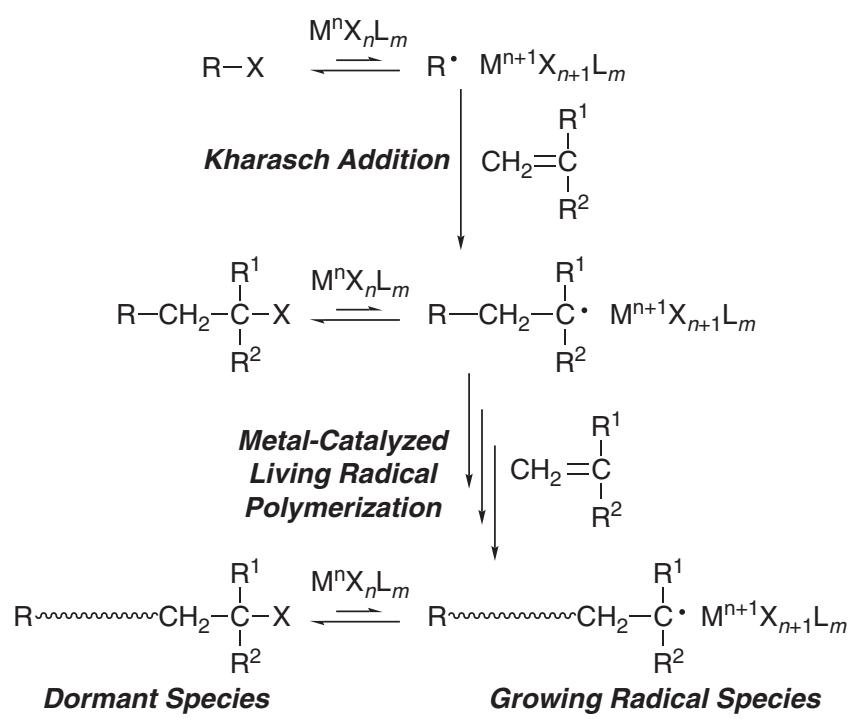

Figure 1 Evolution of the Kharasch addition reaction into metal-catalyzed living radical polymerization.

We originally discovered the ruthenium catalytic systems ${ }^{1}$ and then expanded the systems to other metals, such as iron, nickel, rhenium and manganese. The details on how we discovered the catalytic systems can be found in our previous reviews. ${ }^{7,9}$ In contrast, the most extensively used catalysts are based on copper with nitrogen ligands, which were separately developed by many research groups, including Matyjaszewski, Percec, Haddleton and others ${ }^{2-4,12-17}$ (The reaction mechanisms for the metal-catalyzed living radical polymerization and ATRP are supposed to be the same. Although the former name is mostly used in this review, it never intends to exclude the latter. Thus, the metal-catalyzed living radical polymerization also covers ATRP in the contexts.).

As suggested by the reaction mechanism, the polymerizations are affected by various factors or parameters such as the central metal atom, its ligands, the halogen originating from the initiator, the initiating radical species derived from the initiator, the monomer, the solvent and the temperature. Thus, the effects of all these factors and parameters should be considered for further development of the polymerizations. In particular, there has been tremendous effort to design catalytic systems, including the central metal atom, its oxidation state and the ligands for the metal as well as the halogen and initiating radical species derived from the initiators, to provide finer controllability, higher activity, wider versatility and a more robust nature of the catalytic systems. Thus, a wide variety of conjugated monomers, such as methacrylates, acrylates, styrenes (Sts), acrylamides and acrylonitrile, can now be polymerized in a controlled fashion, although a truly well-controlled radical polymerization of unconjugated monomers such as vinyl acetate (VAc) is still one of the most challenging topics in metal-catalyzed living radical polymerizations. ${ }^{6-17}$ In addition, the amounts of the metal catalyst used in the polymerizations have decreased owing to the evolution of the active catalysts or the addition of reducing agents for the oxidized metal catalysts. However, these are still challenges for industrial applications.

Along with the significant developments of initiating systems for the living radical polymerizations of various monomers, the synthesis of a wide variety of well-defined polymers with controlled architectures has now become possible (Figure 2). ${ }^{6-17}$ They include not only well-known controlled polymer structures such as end-functionalized, block, graft and star polymers, but also other more complicated or
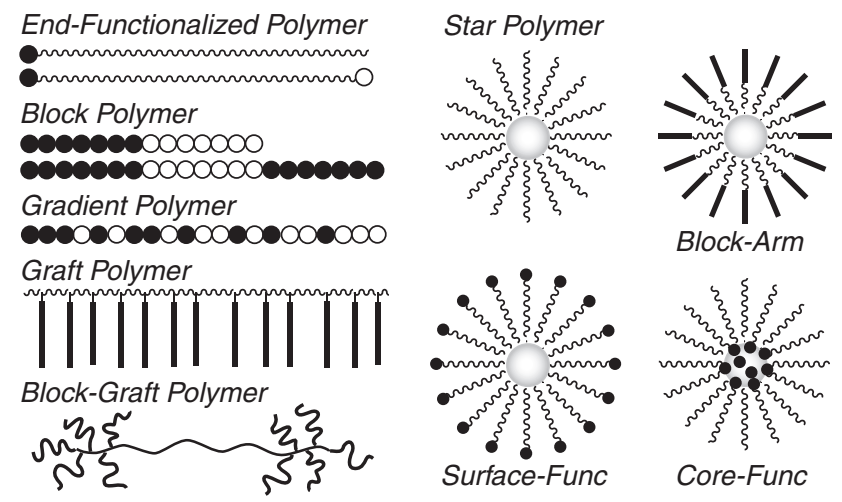

Figure 2 Well-defined polymer structures prepared by living radical polymerization.

unique structures, which have been extremely difficult to synthesize, such as gradient polymers, ring polymers and multiple controlled structures. In particular, for the precision synthesis of these highly ordered structures, metal-catalyzed systems are the most preferable methods in comparison to other living radical polymerization systems for the following reasons. Metal-catalyzed living radical polymerization does not require other carbon radical sources, which may generate new polymer chains as byproducts, and is versatile for almost all conjugated vinyl monomers without changing the terminalcapping group, in which halogen atoms, such as chlorine or bromine, can be used. These advantages are not found in other major living radical polymerizations, ${ }^{34}$ such as nitroxide-mediated polymerizations, which are not suitable for controlling methacrylate homopolymerization, and reversible addition fragmentation chain-transfer polymerizations, which require the use of a radical initiator to generate the radical species to induce the reversible activation of the C-S dormant species.

Another important structural parameter to be controlled in radical polymerization is the stereochemistry or tacticity of the polymer main chain, because it significantly affects the polymer properties, such as the mechanical strength and thermal resistance or stability. The control of the stereochemistry in radical polymerization is still one of the most important and challenging topics in polymer synthesis. Although the stereochemical control of radical polymerization has been achieved for specially designed monomers such as bulky monomers, in special confined spaces such as meso-pores, or in the solid state, such as monomer crystals, it is rather limited to these special cases and cannot be used for common vinyl monomers. ${ }^{38}$ However, over the past 10 years, there have been significant developments in controlling steric structures during the radical polymerization of the common polar vinyl monomers using bulky fluorinated alcohols as solvents or lanthanide triflates as Lewis acid additives, as discovered by Okamoto and co-workers (Figure 3).$^{39}$ These acidic compounds can coordinate to the carbonyl groups of the polar monomers and around the growing chain ends to restrict the free rotation of the propagating radical species to induce the stereospecific propagation. Another further control of radical polymerization is the dual control of the polymer molecular weight and tacticity, which have not yet been fully attained. ${ }^{38,40-42}$

This review covers recent developments in metal-catalyzed living radical polymerization, focusing on our research studies, including the metal-catalytic system, the precision synthesis of well-controlled polymers, and the simultaneous control of the molecular weight and tacticity using metal-catalyzed stereospecific living radical polymerizations. Although there has been great progress in other 
Solvent-Mediated

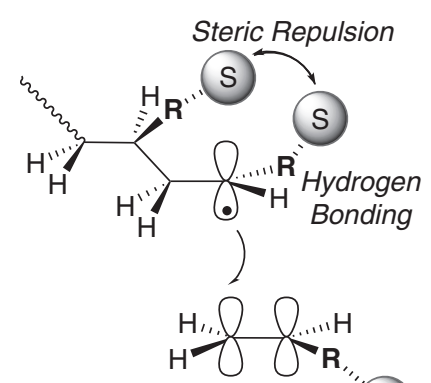

Syndiospecifc
Propagation

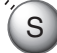

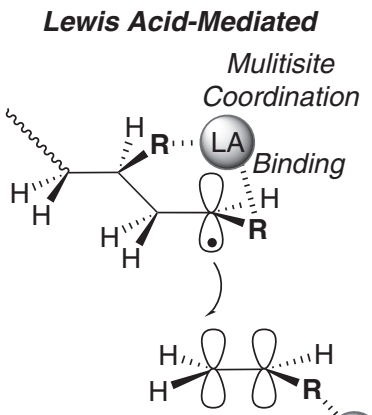

Isospecifc
Propagation

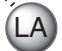

Figure 3 Stereospecific radical polymerization of polar monomers mediated by a solvent and a Lewis acid.

systems, ${ }^{34}$ this review will not systematically cover the other systems because of the limitation of space and the tremendous number of published papers related to these subjects.

\section{METAL CATALYTIC SYSTEMS}

One of the most important challenges for the further development of metal-catalyzed living radical polymerizations is to find more active and versatile catalysts from both the mechanistic and industrial viewpoints. The advent of novel catalytic systems with higher activity and versatility not only offers new insight into the mechanism of the metal-catalyzed living radical polymerization, but also increases the opportunities for industrial application by reducing the amount of metal catalysts used and of metal residues in the products, and by providing a wide variety of accessible, well-defined polymers with controlled architectures.

Among the various strategies to increase the catalytic activity, the use of electron-donating ligands for ruthenium and iron catalysts, in which the lowered redox potential of the metal catalyst due to the ligands contributes to the activation of the carbon-halogen terminal, has proven effective. ${ }^{9,10}$ For this approach, we have introduced electron-donating cyclopentadienyl derivative ligands, such as indenyl (Ind), ${ }^{43}$ pentamethylcyclopentadienyl $\left(\mathrm{Cp}^{\star}\right)^{44}$ and aminoindenyl ${ }^{45}$ groups on the ruthenium complex, and found that they are effective for inducing fast and/or versatile living radical polymerizations of conjugated vinyl monomers (Figure 4). ${ }^{46}$ Once these cyclopentadienyl-based ruthenium complexes were found to be better for living radical polymerizations, they were also successfully used for the Kharasch addition reaction of low-molecular weight compounds. ${ }^{47,48}$

The ruthenium $\mathrm{Cp}^{*}$-complex $\left[\mathrm{Ru}\left(\mathrm{Cp}^{*}\right) \mathrm{Cl}\left(\mathrm{PPh}_{3}\right)_{2}\right]$ in particular gave well-controlled polymers with narrow molecular weight distributions (MWDs) from three different types of conjugated vinyl monomers, methyl methacrylate (MMA), methyl acrylate (MA) and St, via the reversible activation of the stable and relatively strong carbon-chlorine bond originating from the common initiator $\left[\mathrm{H}-(\mathrm{MMA})_{2}-\mathrm{Cl}\right]$ (Figure 5). ${ }^{44}$ The use of the $\mathrm{C}-\mathrm{Cl}$ bond as the dormant species is better in comparison to the weaker and less stable $\mathrm{C}-\mathrm{Br}$ and $\mathrm{C}-\mathrm{I}$ bonds because it preserves the high chain-end functionality of the halide groups, which can be efficiently used for block copolymerization. Although it has not been verified that the lower redox potential guarantees a fast reversible interconversion between the dormant and active species, this strategy seems effective at least for a series of well-defined metal complexes with similar structures. $^{46}$

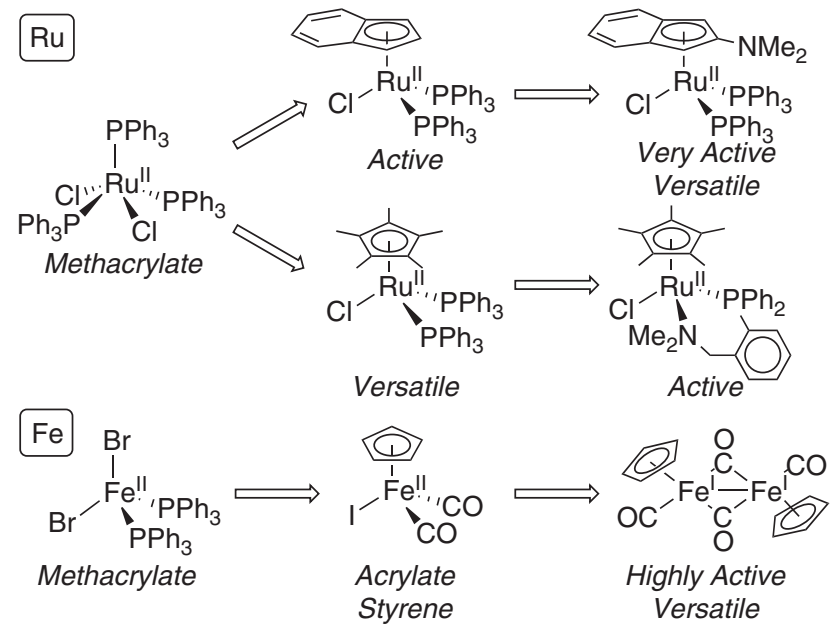

Figure 4 Evolution of ruthenium and iron catalysts for living radical polymerization.

In addition to the use of isolated, well-defined transition metal complexes, in situ modification of the catalyst or the system can increase the catalytic activity and versatility. The first ruthenium complex, $\mathrm{RuCl}_{2}\left(\mathrm{PPh}_{3}\right)_{3}$, requires an additive such as aluminum alkoxide to induce fast and effective living radical polymerizations. ${ }^{1,49}$ Later on, amine additives were shown to be more effective for faster living radical polymerizations with this ruthenium complex as well as other ruthenium complexes, such as $\mathrm{Ru}(\mathrm{Ind}) \mathrm{Cl}\left(\mathrm{PPh}_{3}\right)_{2}$ and $\mathrm{Ru}\left(\mathrm{Cp}^{*}\right) \mathrm{Cl}\left(\mathrm{PPh}_{3}\right)_{2} \cdot{ }^{50-52}$ For some combinations of the ruthenium complexes and amine additives, in situ ${ }^{1} \mathrm{H}$ nuclear magnetic resonance spectroscopy analyses suggested the formation of novel complexes by ligand exchange or other reactions, although the isolation of these amine-coordinated complexes was not achieved. In addition, despite the lack of visible spectral changes in the $\mathrm{Ru}(\mathrm{Ind}) \mathrm{Cl}\left(\mathrm{PPh}_{3}\right)_{2}$ with $n-\mathrm{Bu}_{2} \mathrm{NH}$, much faster living radical polymerizations proceeded with this combination. Given the higher affinity of ruthenium for a phosphine than an amine, additional amines might dynamically form amine-coordinated complexes or reactive vacant sites on the ruthenium complex via displacement of the phosphine ligand due to a large excess of amine additives.

This observation also led to another catalyst design, in which a hemilabile $P, N$-ligand was employed to dynamically generate the coordinatively vacant site for the halogen abstraction and to subsequently kick out the abstracted halogen to the carbon radical species for rapid interconversion between the dormant and active species. ${ }^{53}$ For such bidentate ligands, the isolation of the chelating complexes has been achieved. The isolated ruthenium complex with the chelating $P, N$-ligand indeed induced living radical polymerization without any additives to form polymers with narrow MWDs, although the catalyst lost its activity during the reaction, suggesting a slow decomposition of the catalyst during the catalytic cycle due to the weak coordination of the nitrogen part to the ruthenium. This strategy has been successfully expanded to other potentially bidentate hemilabile bisphosphine monoxide ligands by Sawamoto, Ouchi and co-workers, who reported that the complex could be reduced to 50 p.p.m. for the monomer and that the high polarity of the ligand eased the removal of the catalyst by precipitation of the obtained poly(methyl methacrylate) (PMMA) into methanol. ${ }^{54}$

The use of lower oxidation state metals is another route for generating more active catalysts. In addition to the ruthenium catalyst, 

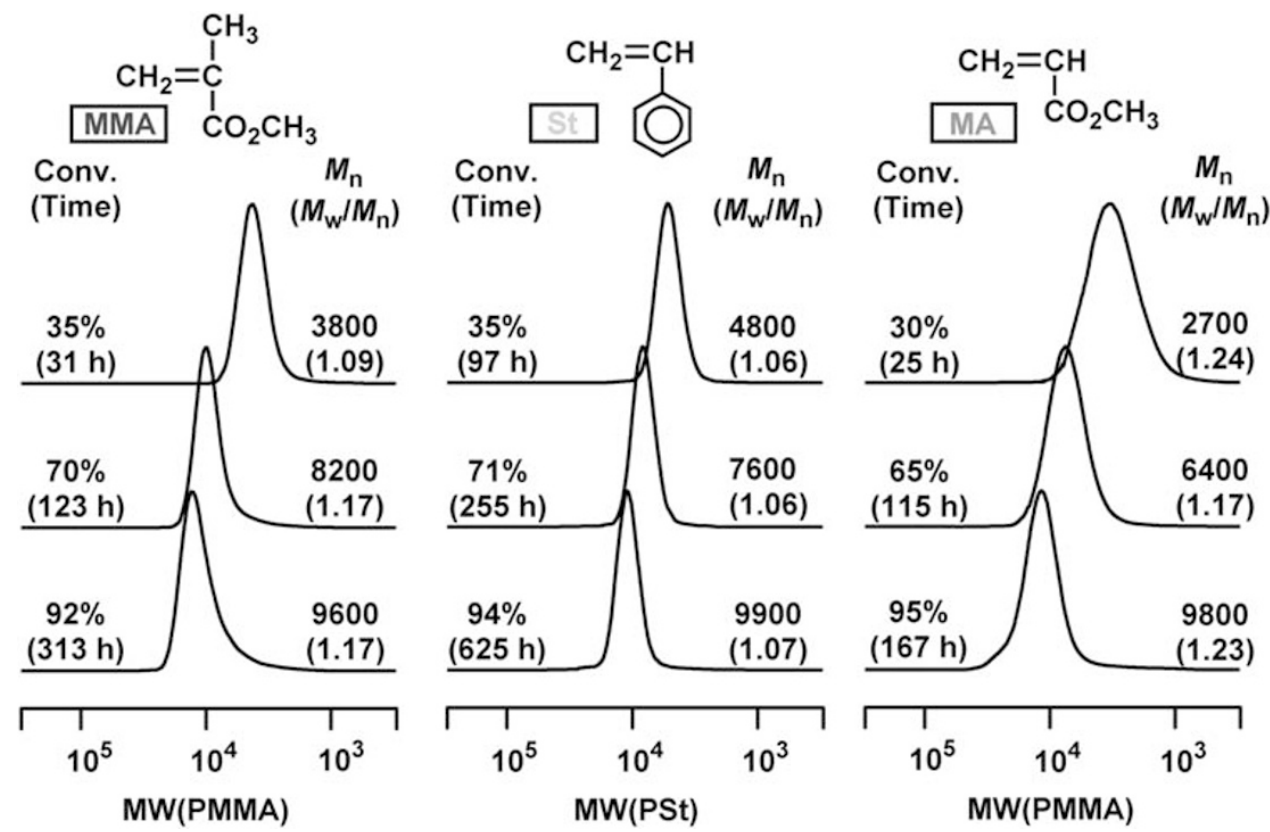

Figure 5 Size-exclusion chromatograms of the polymers obtained in the living radical polymerization of methyl methacrylate (MMA), styrene (St) and methyl acrylate $(\mathrm{MA})$ with $\mathrm{H}-(\mathrm{MMA})_{2}-\mathrm{Cl} / \mathrm{Ru}(\mathrm{Cp} *) \mathrm{Cl}\left(\mathrm{PPh}_{3}\right)_{2} / \mathrm{Al}(\mathrm{O} i-\mathrm{Pr})_{3}$ in toluene at $80^{\circ} \mathrm{C}$ : [monomer $]_{0} /\left[\mathrm{H}-(\mathrm{MMA})_{2}-\mathrm{Cl}\right]_{0} /\left[\mathrm{Ru}(\mathrm{Cp} *) \mathrm{Cl}(\mathrm{PPh})_{2}\right]_{0} /\left[\mathrm{Al}(\mathrm{O} i-\mathrm{Pr})_{3}\right]_{0}=4000 / 40 /$ $4.0 / 40 \mathrm{~mm}$.

the iron(II) catalyst, which belongs to the same group of transition metals in the periodic table and has the same oxidation state $(+2)$ as ruthenium(II), induces similar living radical polymerizations of conjugated monomers, such as methacrylates, acrylates and Sts. ${ }^{55}$ Among the various iron complexes, $\mathrm{FeCl}_{2}\left(\mathrm{PPh}_{3}\right)_{2}$ shows a similar activity to $\mathrm{RuCl}_{2}\left(\mathrm{PPh}_{3}\right)_{3}$ but seems less stable. In a way similar to ruthenium, the $\mathrm{Cp}$ - or $\mathrm{Cp}^{\star}$-based iron(II) complexes showed higher activities and versatilities. ${ }^{56-59}$ We then changed the oxidation state of iron from +2 to +1 by applying the dinuclear $\mathrm{Cp}$ - or $\mathrm{Cp}^{\star}$-based iron(I) complexes $\left[\mathrm{Fe}_{2} \mathrm{Cp}_{2}(\mathrm{CO})_{4}\right.$ or $\left.\mathrm{Fe}_{2} \mathrm{Cp}_{2}{ }_{2}(\mathrm{CO})_{4}\right]$ to various polymerizations. ${ }^{57,59}$ These dinuclear iron(I) complexes proved highly active and induced very fast living radical polymerizations of acrylates, Sts and acrylamides in comparison to the mononuclear iron(II) complexes. Moreover, the dinuclear Cp-based iron(I) complex led to living radical polymerization of a representative unconjugated monomer, VAc, to enable the molecular weight control when coupled with an iodide initiator. ${ }^{60}$ The iron(I) catalyst is active enough to cleave the less reactive dormant carbon-halogen bond derived from VAc, whereas the iodide terminal must be used to achieve controlled molecular weights and narrow MWDs via rapid interconversion between the dormant and highly reactive radical species.

Before our findings on iron(I) living radical polymerization catalysts, lower oxidation metal species such as $\mathrm{Cu}(0)$ had already been employed by Percec et al. for very fast and versatile living radical polymerizations of various monomers including conjugated monomers, such as methacrylates, acrylates, and Sts, and also unconjugated monomers such as vinyl chloride in conjunction with the iodide initiator. ${ }^{17,61,62}$ More recently, Percec and co-workers proposed that the $\mathrm{Cu}(0)$-based living radical polymerization proceeds via a single-electron transfer mechanism under certain conditions and that their systems are highly effective for the very fast living radical polymerization of various monomers, leading to well-controlled high-molecular weight polymers with narrow MWDs. ${ }^{63-66}$ In contrast, the $\mathrm{Cu}(\mathrm{I})$-based systems in the presence of reducing agents, such as tin(II) 2-ethylhexanoate, ascorbic acid, $\mathrm{Cu}(0)$ and radical initiators, also induced an efficient living radical polymerization, in which the accumulated $\mathrm{Cu}$ (II) species changed into the active $\mathrm{Cu}(\mathrm{I})$ species via the reduction by these additives. ${ }^{67-70}$ Although the working mechanisms of $\mathrm{Cu}(0)$ are still controversial and may depend on the conditions, it is clear that the use of lower oxidation metal species is important for constructing highly catalytic systems.

Though conceptually different from these methods, a dinuclear zero-valent manganese complex $\left[\mathrm{Mn}_{2}(\mathrm{CO})_{10}\right]$ has been used as a highly active catalyst for living radical polymerization of various monomers (Figure 6). ${ }^{71-74}$ The dinuclear manganese complex has been employed to generate radical species from alkyl iodides for organic synthesis of low-molecular weight compounds. In this radical reaction, the dinuclear complex generates a mononuclear manganese radical species $\left[\cdot \mathrm{Mn}(\mathrm{CO})_{5}\right]$ under visible light and then abstracts iodine from even secondary and primary alkyl iodides to generate unstable carbon radical species. This complex was thus employed for the living radical polymerization of VAc in conjunction with an alkyl iodide initiator $\left[\mathrm{ICH}_{2} \mathrm{CO}_{2} \mathrm{C}_{2} \mathrm{H}_{5}\right]$ under weak visible light at $40{ }^{\circ} \mathrm{C}$ to induce a very fast polymerization, in which the monomer conversion reached $90 \%$ within $2 \mathrm{~h}$ at $40{ }^{\circ} \mathrm{C} .{ }^{71}$ The polymers obtained had controlled molecular weights, which could be increased up to $M_{\mathrm{n}}=1.4 \times 10^{5}$ by varying the feed ratio of VAc to the iodide initiator, although the MWDs were slightly broader $\left(M_{\mathrm{w}} / M_{\mathrm{n}}=1.2-2.2\right)$. The manganese complex works catalytically for the C-I terminal, where the amount of the complex can be reduced down to $0.025 \mathrm{~mol} \%$ of VAc ( $\sim 100$ p.p.m.) or to $5.0 \mathrm{~mol} \%$ of R-I. In addition to VAc, conjugated monomers such as MA and St can be polymerized in a controlled fashion by this system, indicating the wide versatility for not only conjugated but also unconjugated monomers. It is distinguishable from most of the other metal-catalyzed living radical polymerizations, where the control of the molecular weighs is difficult for unconjugated monomers. 


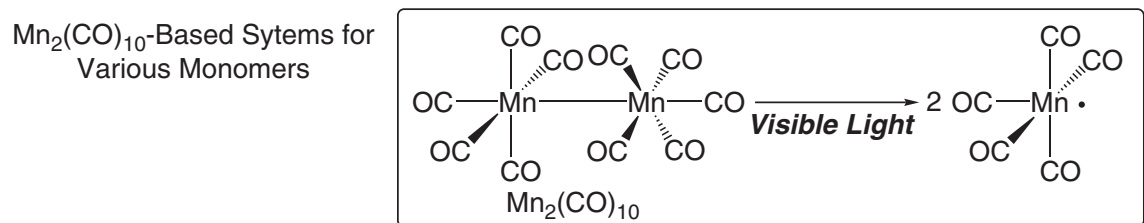

a

Living Radical Polymerization of VAc, MA, and St
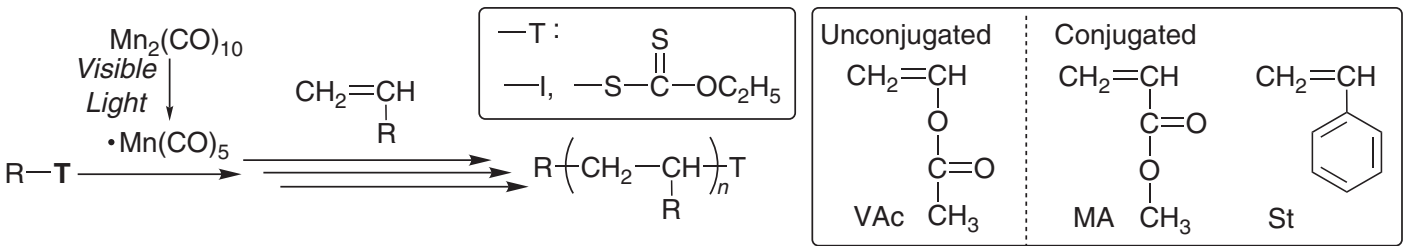

b

Living Radical Copolymerization of MA/VAc and MA/Hex

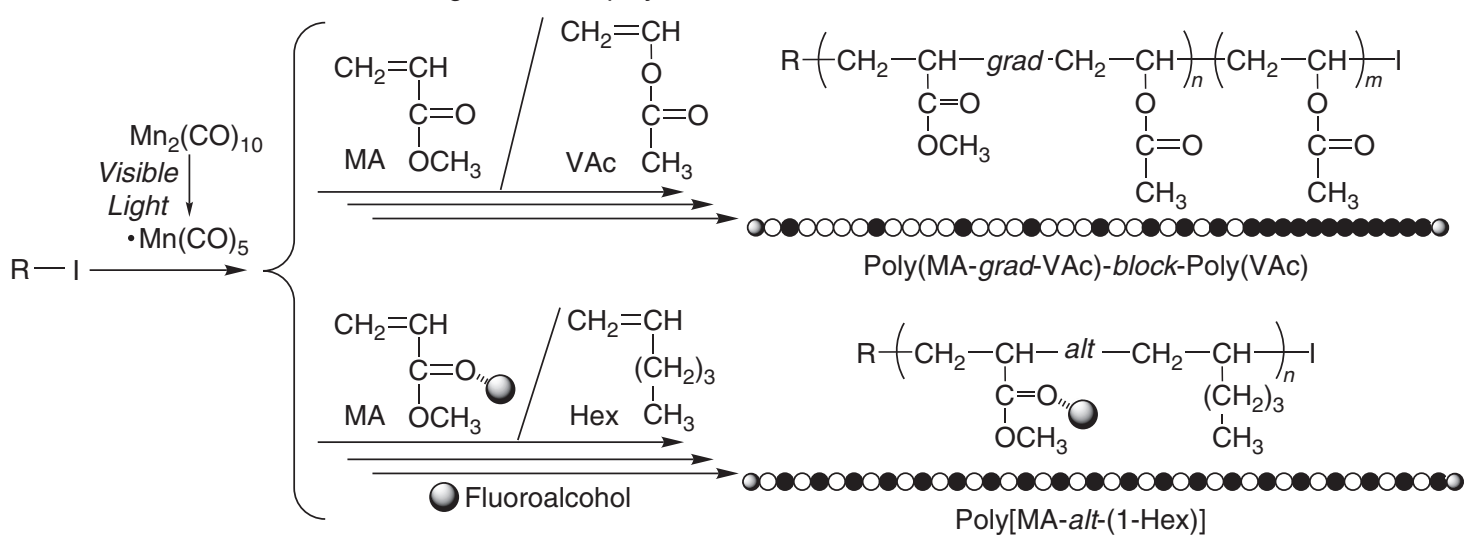

Figure $6 \mathrm{Mn}_{2}(\mathrm{CO})_{10}$-induced living radical polymerization of vinyl acetate (VAc), methyl acrylate (MA) and styrene (St) (a) and living radical copolymerization of methyl acrylate/vinyl acetate and methyl acrylate/1-hexene (Hex) (b).

The manganese-based system has been further applied for controlled radical copolymerization of MA and VAc, conjugated and unconjugated monomers, respectively. ${ }^{72}$ Both monomers are simultaneously consumed, whereas MA is polymerized faster than VAc because of its higher copolymerizability. The resulting polymers possess block-like copolymer structures comprised of gradient segments of MA and VAc, where the content of the latter gradually increases, and homopoly(VAc) segments. This success is due to the wide versatility of the manganese system to various monomers, even with highly different reactivities. It can also be applicable for the controlled radical copolymerization of MA and 1-hexene, a non-polar olefin without any radical homopolymerizability, resulting in MA-rich copolymers with controlled molecular weights. ${ }^{73}$ The additional use of fluoroalcohols as the solvent enhances the copolymerizability to give copolymers with up to $50 \mathrm{~mol} \%$ content of 1-hexene depending on the conditions. The enhanced copolymerizability can be ascribed to the hydrogen-bonding interaction between the carbonyl group of MA or the growing radical chain end derived from MA, where the highly electron-deficient monomer and radical species preferentially undergo cross-propagation with the more or less electron-rich 1-hexene radical and 1-hexene monomer, respectively.

These $\mathrm{Mn}_{2}(\mathrm{CO})_{10}$-induced polymerizations are photoresponsive and thus do not occur in the dark, whereas the living propagation continues during the visible light period. ${ }^{71}$ Although the polymerization is triggered by activation of the C-I bond of the initiator by
- $\mathrm{Mn}(\mathrm{CO})_{5}$ generated from $\mathrm{Mn}_{2}(\mathrm{CO})_{10}$ under visible light, the degenerative iodine transfer process also contributes to the fast interconversion between the dormant $\mathrm{C}-\mathrm{I}$ and growing radical species to control the chain lengths of the resulting polymers. This situation is almost always inevitable for the controlled radical polymerization with the $\mathrm{C}-\mathrm{I}$ terminal. However, the manganese radical species does not directly add to the $\mathrm{C}=\mathrm{C}$ bond of the vinyl monomers and does not initiate the radical polymerizations by itself. The dinuclear manganese complex has been further coupled with thioester compounds as initiators and/or reversible addition fragmentation chain-transfer agents to induce living radical polymerization of various monomers including VAc, MA and St via a similar manganese-mediated activation of the C-S terminal. ${ }^{74}$ The polymerizations were well controlled to give the polymers with controlled molecular weights and welldefined chain end groups originating from the thioester compounds. However, in these polymerizations, a similar degenerative transfer mechanism via the reversible addition fragmentation chain-transfer process may also contribute to the control in addition to the direct activation of the $\mathrm{C}-\mathrm{S}$ bond by the manganese radial species.

Another crucial problem associated with the metal catalysts for living radical polymerization is the concomitant of residual metal species in the polymer products, which could be toxic or environmentally unfriendly and often deteriorate the polymer properties for their applications. One of the most promising solutions for this issue from an environmental viewpoint is to develop efficient iron-based catalytic 
systems due to their essential non-toxicity and natural abundance. As described above, various iron-based catalytic systems have been developed. ${ }^{55-60,75,76}$ In particular, Nagashima and co-workers recently reported recyclable iron catalysts with nitrogen-based ligands for living radical polymerizations. ${ }^{77,78}$ However, almost all of the ironbased systems consist of lower oxidation state iron(II) or iron(I) species in the presence of the appropriate ligands coupled with halide initiators. Although the iron(III) species is more stable than iron(II), it is known as a radical inhibitor and is thus inactive for the activation of the carbon-halogen bond because of its higher oxidation state. The use of the more stable iron(III) species as possible catalysts or as precursor catalysts is more practical because of its easy handling under air. The use of iron(III) species as a precursor for the living radical polymerization catalysts had already been accomplished in the presence of a radical initiator for the reverse ATRP, ${ }^{79,80}$ where the iron(III) halide is reduced to the iron(II) species by the carbon radical species generated from the radical initiator along with the formation of the carbon-halogen dormant species. Another strategy is to use reducing agents, such as tin(II) compounds, sugar and ascorbic acid, in conjunction with the iron(III) species, where an active iron(II) species is generated upon the reduction. ${ }^{81}$

In contrast, examining the effects of iron(III) species on the iron(II)-catalyzed living radical polymerization with an organic chloride initiator, we accidentally found that $\mathrm{FeCl}_{3}$ coupled with phosphine or amine ligands induces living radical polymerization of MMA and St in the presence of a halide initiator without using any intentionally added radical initiators or reducing agents. ${ }^{82}$ Although $\mathrm{FeCl}_{3}$ prohibited the radical polymerization without the ligands, it induced living radical polymerization from the carbon-chloride bond upon the addition of the phosphine ligand. The UV-vis analysis of the mixture of $\mathrm{FeCl}_{3}$ and phosphine ligand suggested that the phosphine induced disproportionation of $\mathrm{FeCl}_{3}$ into the iron(III) anion [ $\mathrm{Fe}(\mathrm{III}) \mathrm{Cl}_{4}{ }^{-}$] and most likely the iron (III) cation $\left[\mathrm{Fe}(\mathrm{III}) \mathrm{Cl}_{2}^{+}\right]$. Under such conditions, the $\mathrm{FeCl}_{2}{ }^{+}$complexed with the phosphine or amine ligand serves as an activator for the carbon-halogen terminal via a reversible redox reaction, probably due to the amine or phosphine moiety. Although the mechanism has not yet been completely clarified, similar systems consisting of an iron(III) halide, some ligands and a halide initiator, without any intentionally added reducing agents, have recently been reported by other researchers. ${ }^{83-86}$

\section{PRECISION SYNTHESIS OF WELL-DEFINED POLYMERS}

Such significant developments in various living radical polymerizations have dramatically widened the scope of the accessible well-defined polymers with various architectures in comparison to living ionic and coordination polymerizations due to the robustness of the growing radical species to polar functional groups and the applicability for a wide variety of vinyl monomers. ${ }^{6-17}$ Among the various metal catalysts for living radical polymerizations, ruthenium complexes show a relatively high tolerance to polar functional groups due to the lower oxophilicity of the ruthenium center and their non-ionic character.

By using these properties, various functional groups have been directly introduced onto the end groups or the side chains of polymers to result in well-defined end- or side-chain-functionalized polymers with controlled molecular weights, respectively. More specifically, organic-halide initiators functionalized with hydroxyl, amino and amide groups were used as initiators for ruthenium-catalyzed living radical polymerizations to give the corresponding end-functionalized polymers with controlled molecular weights, narrow MWDs and controlled $\alpha$-chain end functional groups (Figure 7). ${ }^{87}$ Most of these a Functionalized Initiators<smiles>CCCNC(=O)C(Cl)c1ccccc1</smiles>

b End-Capping Agents

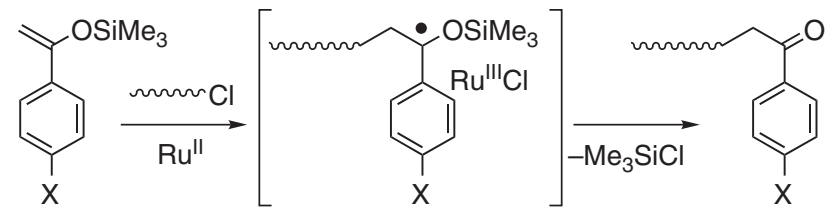

(X: $\mathrm{H}, \mathrm{OCH}_{3}, \mathrm{~F}, \mathrm{Cl}, \mathrm{OSiMe}_{3}$ )

Figure 7 Functionalized initiators (a) and end-capping agents (b) for ruthenium-catalyzed living radical polymerization.

functionalized initiators are easily prepared from the acyl halide and the corresponding functionalized alcohol. In contrast to various $\alpha$ chain end groups, functionalization of the $\omega$-chain end is relatively difficult because of the stable covalent carbon-halogen bond in comparison to the ionic living polymerizations, where direct and fast ionic termination reactions are possible. However, special reagents or reactions can be used for the effective chain-end functionalization irrespective of the limitation. A St derivative with an $\alpha$-silyloxy group can add to the radical chain end and subsequently form the ketone terminals via elimination of the silyl group in a way similar to the addition fragmentation process. ${ }^{88,89}$ For the side-chain functionalized polymers, a wide variety of functionalized monomers carrying hydroxyl, amino, epoxy and other groups can be directly polymerized without protection of these polar groups, although such examples are omitted in this review. ${ }^{6-17}$

The excellent living character and versatility of metal-catalyzed living radical polymerizations have enabled the precise synthesis of a wide variety of well-defined block polymers. ${ }^{6-17}$ Significantly, varied block copolymers have been synthesized from radically polymerizable monomers with various substituents. They are usually prepared via simple processes, in which the prepolymers are synthesized by the living radical polymerization of the first monomer, followed by the isolation of the first living prepolymers with a reactive carbon-halogen terminal, usually by the precipitation and living radical polymerization of the second monomer upon the addition of the metal catalysts again. In addition, a much wider series of block copolymers have been obtained via combination with other various living polymerizations including radical, ionic, coordination and condensation mechanisms or with chain-end modification of the other polymers with the halide groups. One of the most important requisites for the metal-catalyzed living radical polymerization is to put a reactive carbon-halogen bond at the terminals of the prepolymers for the block polymerizations.

As for star polymer synthesis, there are several possible methods similar to the other living polymerizations. For the synthesis of star polymers with a well-defined number of arm chains using living polymerization, there are principally two methods, that is, the multifunctional initiator or terminator methods. However, in the latter case, 
<smiles>CC(Cl)C(=O)Oc1ccc(C(C)(c2ccc(OC(=O)C(Cl)Cl)cc2)c2ccc(OC(=O)C(Cl)Cl)cc2)cc1</smiles>

Tetrafunctional

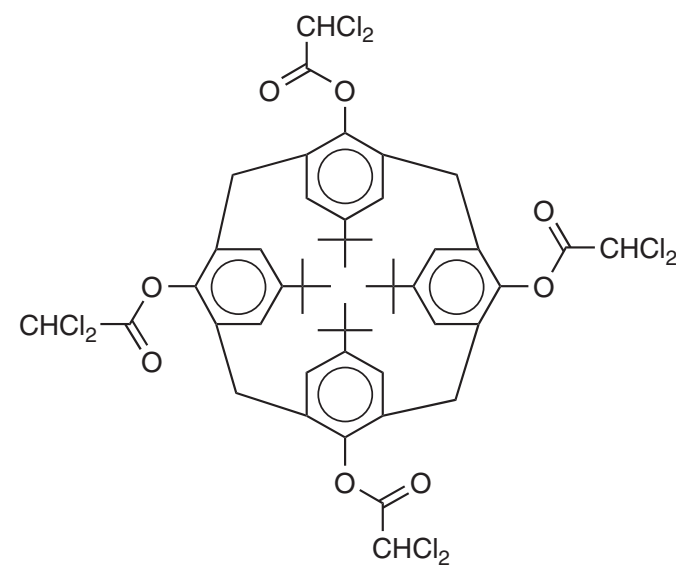

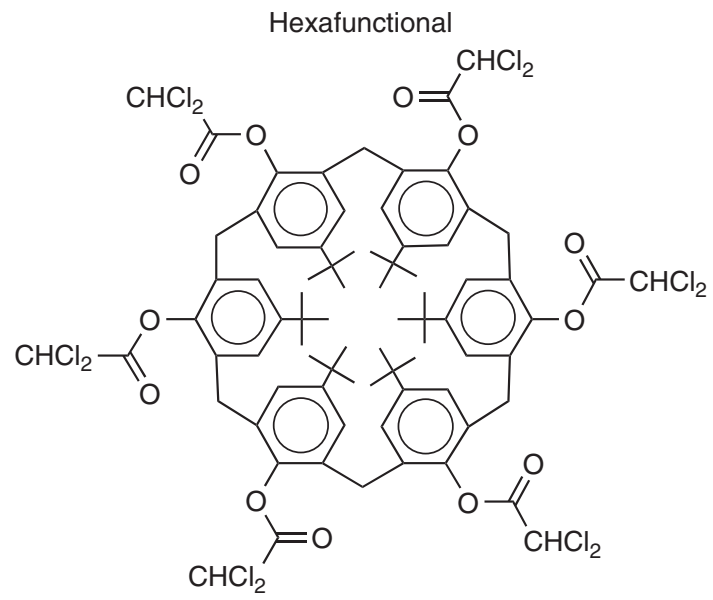

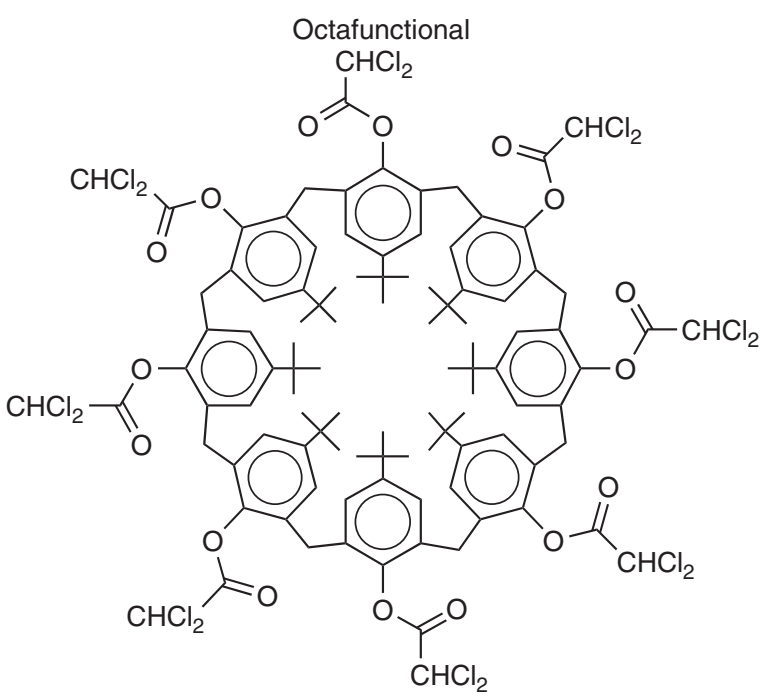

Figure 8 Multifunctional initiators for the ruthenium-catalyzed living radical polymerization.

for the metal-catalyzed living radical polymerization, the quantitative chain-end substitution of the halide at the terminal is relatively difficult because of the stable bond and is thus rarely employed. In the former case, many star polymers have been synthesized from multifunctional initiators possessing multiple reactive carbon-halogen bonds in a single molecule (Figure 8). ${ }^{90,91}$ These initiators can be synthesized from polyhydric alcohols or phenols and an acyl halide possessing the $\mathrm{C}-\mathrm{X}$ bond as the initiating site for the living radical polymerization. Although star polymers with well-defined arm numbers and controlled arm-chain lengths can be obtained by this method, the synthesis and the isolation of the multifunctional initiators or the polyhydric compounds are often tedious and difficult.

Another route to the synthesis of star or star-shaped polymers relies on the use of divinyl or multivinyl compounds as linking agents. In the core-first method, the divinyl compounds are first crosslinked to form a soluble microgel followed by the living polymerization of vinyl monomers from the core. Although this method often results in the formation of insoluble products due to the difficulty of controlling the reaction conditions, it has also been successfully applied to ATRP. ${ }^{92}$ The other method is based on the linking reaction of linear polymers prepared by the living polymerization upon the addition of the divinyl compounds, in which the microgel core can be easily solubilized by the attached arm polymer chains. This method has now been widely applied to the synthesis of various star polymers because of the easier method, where only the addition of divinyl compounds to the living linear polymers can lead to the formation of high molecular weight and large number of arm chains. However, the number of arm chains has a statistical distribution for each star polymer.

By applying the linking reaction to the ruthenium-catalyzed living radical polymerization, we have shown that star polymers with high molecular weights and narrow MWDs can be synthesized in a relatively high yield (Figure 9). ${ }^{93,94}$ The star polymers obtained possess globular structures that are $\sim 10 \mathrm{~nm}$ in diameter with $10-10^{2}$ arm chains depending on the conditions. In addition to the efficient formation of high-molecular weight star polymers, functional moieties, such as hydroxyl, amino and amide groups, can be introduced into various parts of the star polymers, that is, arm chains of homopolymers, random copolymers, block polymers, surficial end-groups of arm polymers and the core of star polymers (see Figure 2). ${ }^{95-103}$

In particular, for the synthesis of core-functionalized star polymers, the use of functionalized divinyl compounds possessing hydroxyl and amide groups in the linker between the two vinyl groups has proven effective, and high-molecular weight star polymers with many arm 

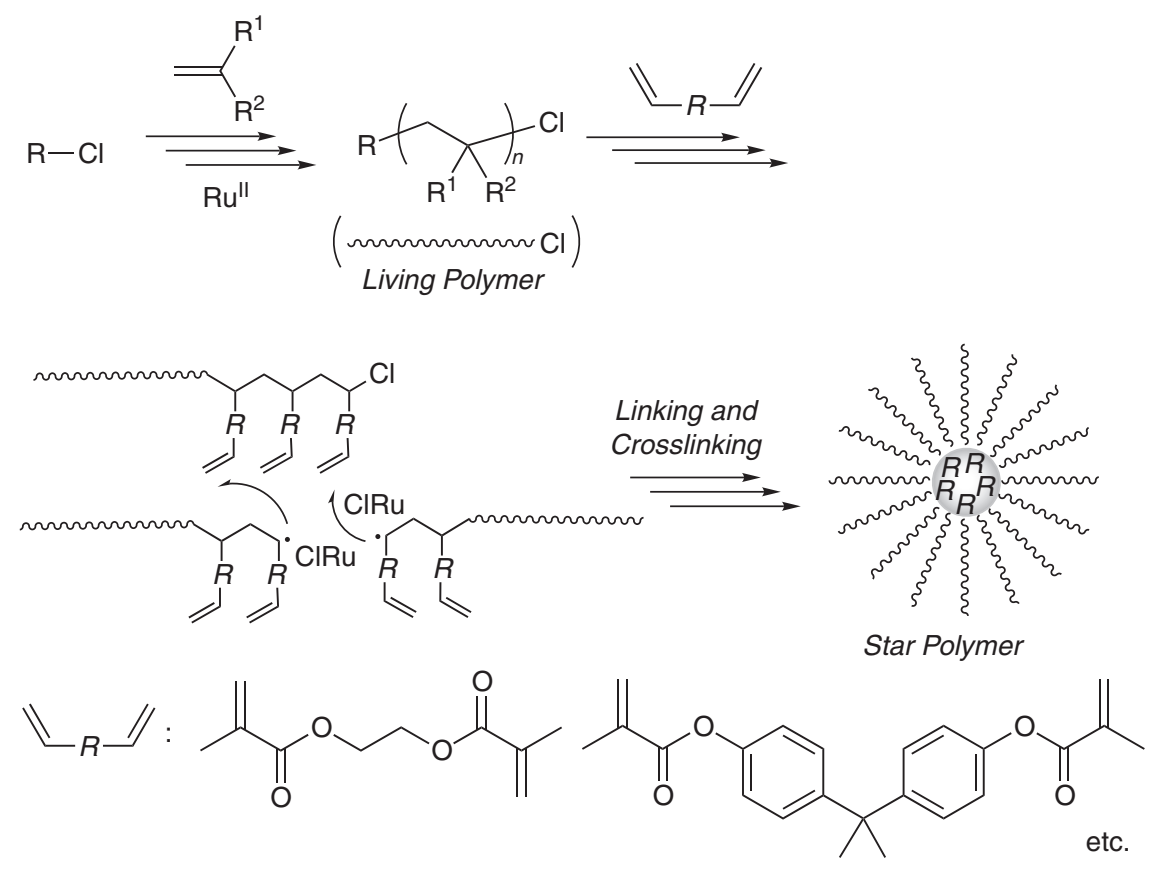

Figure 9 Star polymers produced by the linking reaction with divinyl compounds in the ruthenium-catalyzed living radical polymerization.
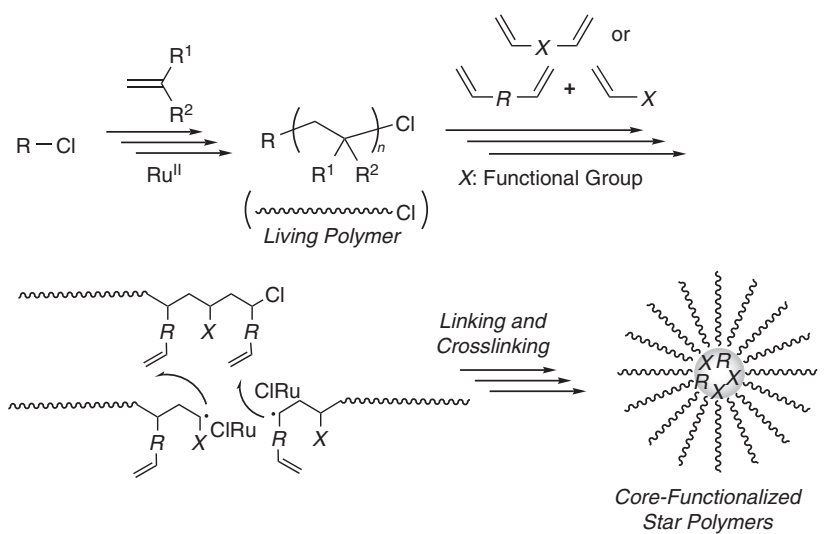

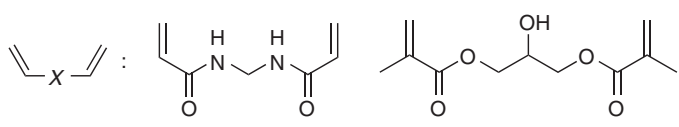

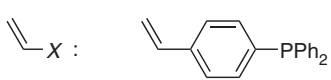

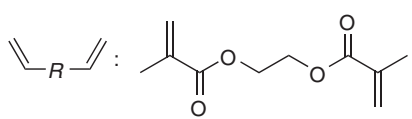

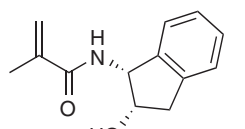

$\mathrm{HO}$

Figure 10 Core-functionalized star polymers produced by the linking reaction with functionalized divinyl compounds or with the mixture of divinyl compounds and functionalized vinyl monomers in the ruthenium-catalyzed living radical polymerization.

chains can be obtained in high yield (Figure 10). ${ }^{97,98}$ The polar functional groups densely packed in the core can interact with lowmolecular weight polar compounds, such as carboxylic acids, alcohols and amines, via hydrogen bonds to reversibly capture them.

Another effective and simpler method to introduce the functional groups into the core of star polymers is to 'copolymerize' functiona- lized monovinyl monomers with divinyl compounds upon the linking reaction of the linear arm polymer chains. In this approach, it is unnecessary to prepare the functionalized divinyl compounds before the polymerization, but the functionalized monovinyl monomers should have a good 'copolymerizability' with the divinyl compounds for the efficient functionalization of the cores, as well as high-yield formation of the star polymers. Using this approach, we put phosphine moieties into the core of the star polymer with PMMA arms via a linking reaction of the living PMMA chains with ethylene glycol dimethacrylate in the presence of 4-diphenylphophino St. ${ }^{99}$ Along with the linking reaction by the divinyl compounds, the phosphinesubstituted Sts were copolymerized to form a functionalized core with the phosphine group. In addition, the ruthenium catalyst was simultaneously introduced into the core of the star polymers via coordination of the phosphine moiety of the vinyl monomer to the ruthenium center because of the ligand exchange reaction with triphenylphosphine. In particular, a typical number of ruthenium atoms incorporated into the core was estimated to be around 100, indicating that many ruthenium catalytic sites are contained in the nanometer-sized core of the star polymers. The ruthenium-containing star polymers were then used as microgel-core catalysts for the oxidation of alcohols into ketones or reduction of ketones into alcohols because similar but low-molecular weight ruthenium complexes with chloride and phosphine groups are known to catalyze such organic reactions. ${ }^{99-102}$ However, the core-functionalized star polymer catalyst is thought to have different properties from those of the normal catalysts because the microgel-core catalysts have densely packed metal catalytic sites surrounded by a number of arm chains. Thus, the core catalytic sites can be solubilized in various solvents depending on the arm chains and protected from the external environments by the arm chains. Several types of star polymers have exhibited a higher catalytic activity than the low-molecular weight catalysts and could be reused without any significant loss of the catalytic activity after the recovery in air. Sawamoto, Terashima and co-workers also reported that the ruthenium in the core could be removed upon the addition of a hydrophilic 

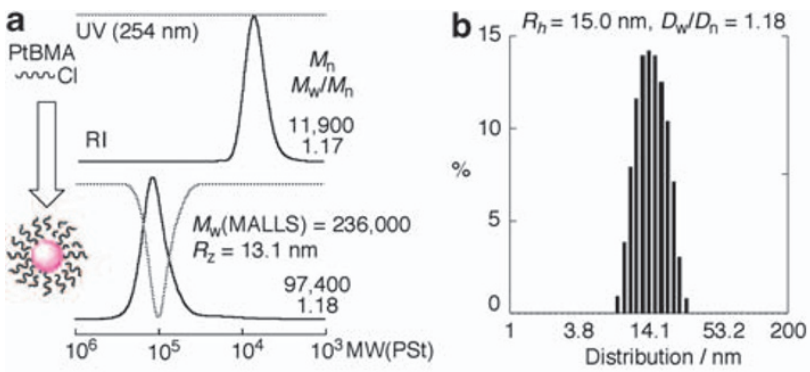

C
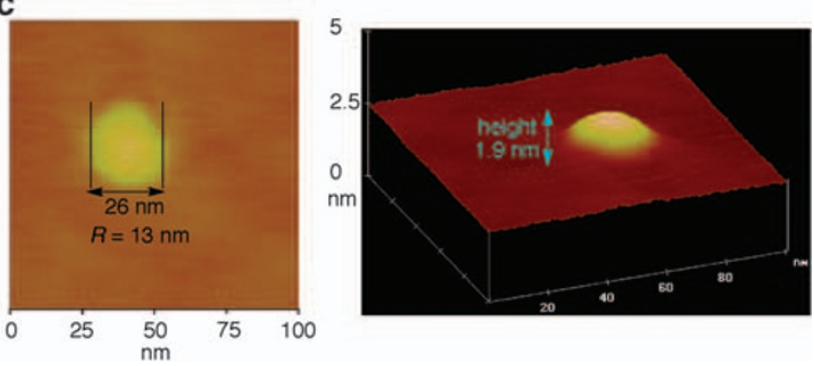

Figure 11 Size-exclusion chromatograms of arm poly(tert-butyl methacrylate) prepared by the ruthenium-catalyzed living radical polymerization and star polymers prepared by the ruthenium-catalyzed linking reaction of the linear arm poly poly(tert-butyl methacrylate) with ethylene glycol dimethacrylate and the chiral methacrylamide ([linear polymer $]_{0} /\left[\mathrm{Ru}(\mathrm{Ind}) \mathrm{Cl}\left(\mathrm{PPh}_{3}\right)_{2}\right]_{0} /$ $\left[n-\mathrm{Bu}_{3} \mathrm{~N}\right]_{0} /[\text { chiral monomer }]_{0} /[\text { ethylene glycol dimethacrylate }]_{0}=1000 / 1.0 /$ $10 / 50 / 100 \mathrm{~mm}$, in toluene/DMF $\left.=1 / 1,80^{\circ} \mathrm{C}\right)(\mathbf{a})$, dynamic light scattering of the star polymers in $\mathrm{CHCl}_{3}$ (b) and atomic force micrography images of the star polymers spread on a mica plate from a $0.1-\mathrm{mg} \mathrm{ml}^{-1}$ DMF solution (c). Ind, indenyl.

phosphine $\left[\mathrm{P}\left(\mathrm{CH}_{2} \mathrm{CH}_{3} \mathrm{OH}\right)_{3}\right]$ to result in an 'empty' core that still possessed the phosphine moieties and that other metals like iron and nickel could be introduced into the core via coordination. ${ }^{10}$

We also examined the introduction of chiral groups into the core of star polymers via the ruthenium-catalyzed linking reaction of the isolated linear polymer chains of tert-butyl methacrylate possessing a dormant $\mathrm{C}-\mathrm{Cl}$ terminal in the presence of ethylene glycol dimethacrylate as a linking agent and a methacrylamide monomer with a chiral aminoalcohol group as a functionalized vinyl monomer. ${ }^{103}$ Along with the simultaneous consumption of the divinyl compound and the chiral vinyl monomer, the molecular weight of the polymers progressively increased to give high-molecular weight star polymers in high yield $\left(M_{\mathrm{n}}=97400, M_{\mathrm{w}} / M_{\mathrm{n}}=1.18\right)$. The absolute molecular weight of the polymers measured by multiangle-laser-light scattering (MALLS) was higher $\left(M_{\mathrm{w}}=236000\right)$ than that obtained by a refractive index detector in size-exclusion chromatography (Figure 11). Furthermore, the number of arm chains was estimated to be around 15 by the size-exclusion chromatography-MALLS analysis of the star polymers and the linear prepolymers. The MALLS study also showed that these polymers have globular structures with a mean radius of gyration of $R_{\mathrm{z}}=13.1 \mathrm{~nm}$. The dynamic light scattering study also revealed that the star polymers had a similar size with a hydrodynamic radius $\left(R_{\mathrm{h}}=15.0 \mathrm{~nm}\right)$ and narrow size distribution $\left(D_{\mathrm{w}} / D_{\mathrm{n}}=1.18\right)$. In addition, the atomic force micrography of the star polymers cast from the diluted solution showed globular objects with 13-nm diameters. The star polymers were active for circular dichroism, where the circular dichroism spectrum was similar to that of the chiral monomer, indicating the formation of the chiral core in the star polymers. The chiral star polymers were then used for the chiral recognition of lowmolecular weight racemic compounds, such as $( \pm)$-binaphthol, where the selective interaction of one enantiomer was confirmed by ${ }^{1} \mathrm{H}$ nuclear magnetic resonance spectroscopy analysis of the mixtures. These results indicate that the functionalization of star polymer cores is promising for the construction of novel functional polymeric materials. Recently, Fréchet and co-workers reported that two star polymers, where one has an acid catalyst in the core and the other has a base catalyst in the core, could coexist via protection of the functionalized groups by the surrounding arm polymer chains and that they induced one-pot, multicomponent, asymmetric cascade reactions. ${ }^{104}$

Another well-defined polymer with a complicated structure that we investigated is the $\mathrm{A}_{\mathrm{x}} \mathrm{B} \mathrm{A}_{\mathrm{x}}$-type block-graft or dumbbell-like copolymer that possesses multiple hard graft chains of the outer A-part and soft mid-blocks of the inner B-part in the $A_{x} B A_{x}$ structure (Figure 12). ${ }^{105-107}$ Such copolymers might have characteristic features in terms of microphase separation and elastomeric or mechanical properties because of their structures, which differ slightly from those of the ABA-type hard-soft-hard triblock copolymers. For synthesis of $\mathrm{A}_{\mathrm{x}} \mathrm{BA}_{\mathrm{x}}$-type copolymers, the ruthenium-catalyzed living radical polymerization of dodecyl methacrylate was first conducted using a bifunctional initiator followed by the subsequent block copolymerization of silyloxyethyl methacrylate to give the ABA-type block copolymers possessing reactive silyloxy pendent groups in the outer A-units. The silyloxy group was then converted into an ester moiety via in situ direct substitution with acyl bromide, which possessed another carbon-bromine bond that could subsequently be employed as initiating sites for the second living radical polymerization of the grafting monomers. The prepolymers or multifunctional macroinitiators thus synthesized were isolated by precipitation and then employed as multifunctional initiators for the second living radical polymerization of MMA or St upon the addition of the appropriate ruthenium catalysts to result in the $\mathrm{A}_{\mathrm{x}} \mathrm{BA}_{\mathrm{x}}$-type block-graft copolymers containing soft middle segments and hard outer graft chains. The lengths of the main and graft chains as well as the contents of each segment can be arbitrarily tuned by the feed ratios of the monomers, difunctional initiators and multifunctional macroinitiators. The polymers obtained had controlled molecular weights $\left(M_{\mathrm{n}}=1-3 \times 10^{5}\right)$ and narrow MWDs $\left(M_{\mathrm{w}} / M_{\mathrm{n}}=1.1-1.3\right)$. The graft structures were confirmed by the dependence of the radius of gyration on the molar masses measured by MALLS and by atomic force micrography imaging of the polymers cast from the dilute solution. In addition, transmission electron microscopy and transmission electron microtomography ${ }^{108}$ revealed a series of morphologies for the copolymers (Figure 13). Morphological changes were observed from the graft-chain 'honeycomb' cylinders to lamellae and inner-block cylinders with increasing graftchain content, whereby the phase diagram was significantly shifted to the lower volume fractions of the larger-number component of the graft segments relative to those of the corresponding ABA triblock copolymers. In particular, cylindrical microphase separation showed highly ordered, hexagonally packed structures. The $\mathrm{A}_{\mathrm{x}} \mathrm{BA}_{\mathrm{x}}$-type copolymers also exhibited the characteristics of a thermoplastic elastomer, which were well related to the microphase structures of the copolymers.

\section{STEREOSPECIFIC LIVING RADICAL POLYMERIZATION}

Another important issue for radical polymerization is the stereochemistry, especially for the common vinyl polymers obtained from commercially available monomers. There have been several attempts to control the stereochemistry in living radical polymerization and in non-living radical polymerization. As described above, metal-catalyzed living radical polymerization was originally developed via the 


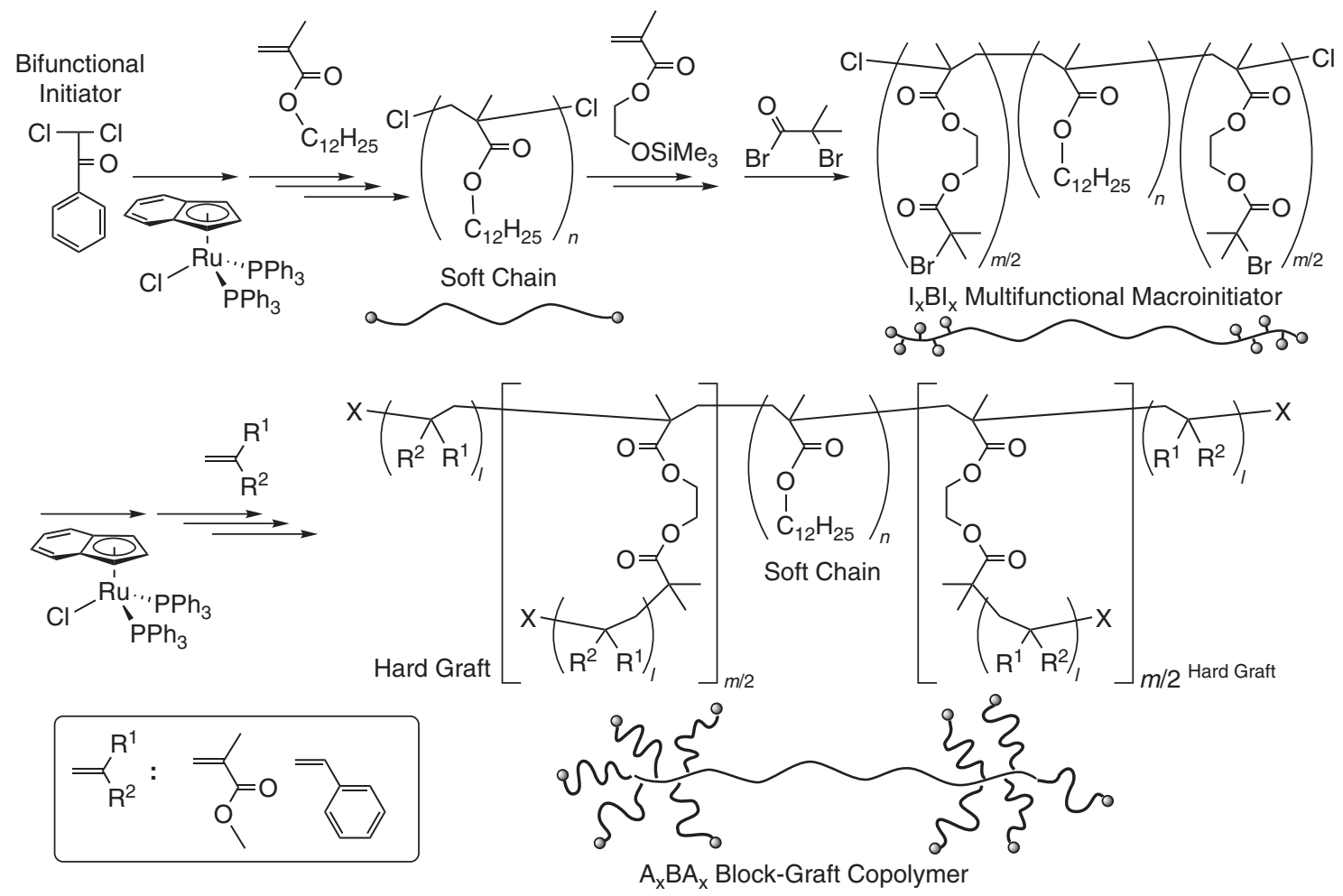

Figure $12 \mathrm{~A}_{x} \mathrm{BA}_{\mathrm{x}}$-type block-graft copolymers with soft middle segments and hard outer grafts produced by the ruthenium-catalyzed living radical polymerization.
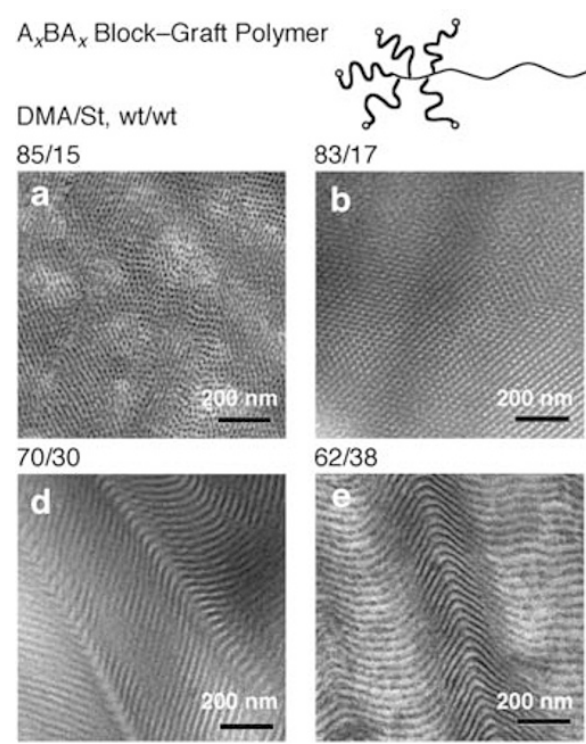

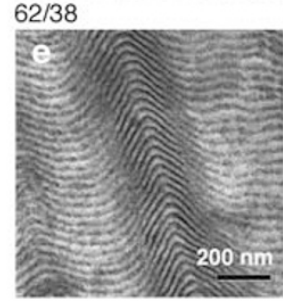

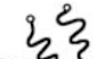

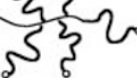

$77 / 23$
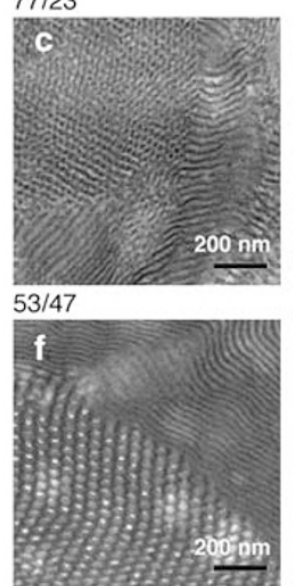

Stained with $\mathrm{RuO}_{4}$ g DMA/St $=83 / 17$
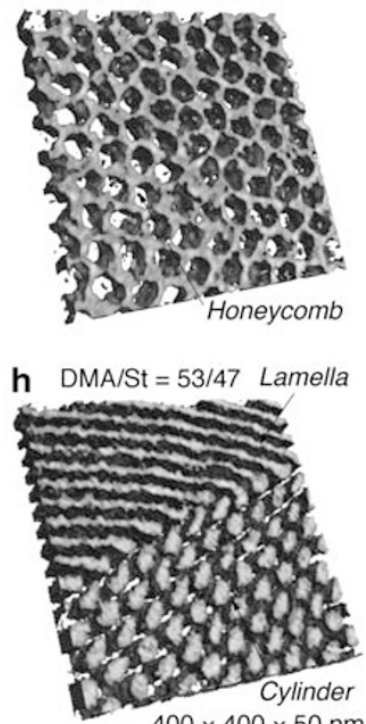

Figure 13 Transmission electron microscopy images of the $A_{x} B A_{x}$ block-graft copolymers $\left(a, M_{n}\right.$ (multiangle-laser-light scattering, MALLS)=161000, $M_{w} /$ $M_{\mathrm{n}}=1.23, \mathrm{~B} / \mathrm{A}=85 / 15 ; \mathbf{b}, M_{\mathrm{n}}(\mathrm{MALLS})=171000, M_{\mathrm{w}} / M_{\mathrm{n}}=1.19, \mathrm{~B} / \mathrm{A}=83 / 17 ; \mathbf{c}, M_{\mathrm{n}}(\mathrm{MALLS})=167000, M_{\mathrm{w}} / M_{\mathrm{n}}=1.23, \mathrm{~B} / \mathrm{A}=77 / 23 ; \mathrm{d}, M_{\mathrm{n}}(\mathrm{MALLS})=186000$, $M_{\mathrm{w}} / M_{\mathrm{n}}=1.27, \mathrm{~B} / \mathrm{A}=70 / 30 ; \mathrm{e}, M_{\mathrm{n}}(\mathrm{MALLS})=202000, M_{\mathrm{w}} / M_{\mathrm{n}}=1.25, \mathrm{~B} / \mathrm{A}=62 / 38 ; \mathrm{f}, M_{\mathrm{n}}(\mathrm{MALLS})=235000, M_{\mathrm{w}} / M_{\mathrm{n}}=1.41$, B/A=53/47) and the threedimensional solid renditions of the poly(DMA) microdomains within a transparent polystyrene matrix $\left(\mathbf{g}\right.$ and $\mathbf{h}: 400 \times 400 \times 50 \mathrm{~nm} ; \mathbf{g}, M_{\mathrm{n}}(\mathrm{MALLS})=171000$, $\left.M_{\mathrm{w}} / M_{\mathrm{n}}=1.19, \mathrm{~B} / \mathrm{A}=83 / 17 ; \mathbf{h}, \mathrm{d}: M_{\mathrm{n}}(\mathrm{MALLS})=235000, M_{\mathrm{w}} / M_{\mathrm{n}}=1.41, \mathrm{~B} / \mathrm{A}=53 / 47\right)$. Stained by $\mathrm{RuO}{ }_{4}$. St, styrene.

evolution of the Kharasch addition into the repetitive addition reaction between the radical species and monomers. For the metalcatalyzed radical addition reaction of low-molecular weight compounds, it was reported that some chiral ruthenium complexes bearing $(+)$ - or $(-)$-DIOP ligands (DIOP=2,3-(isopropylienedioxy)2,3-dihydroxy-1,4-bis(diphenylphosphanyl)butane) induced asymmetric 
radical addition reactions to give optically active adducts (20-40\% ee). ${ }^{109}$ The asymmetric induction was assumed to be due to the radicals that are confined in the coordination sphere of the ruthenium complex with a chiral ligand, although the mechanism was unknown. If such chiral metal complexes could control the stereochemistry or the tacticity of the resulting polymers, the dual control of the molecular weight and the tacticity could be achieved by a singlemetal catalyst. We thus synthesized a series of chiral ruthenium complexes with the (-)-DIOP ligand and employed them as catalysts for the Kharasch addition between $\mathrm{CCl}_{3} \mathrm{Br}$ and the common vinyl monomers, such as St, MMA and MA, and living radical polymerizations of these monomers (Figure 14). ${ }^{110}$ Although $\mathrm{Ru}_{2} \mathrm{Cl}_{4}[(-)$ DIOP $]_{3}$ and $\mathrm{Ru}(\mathrm{Ind}) \mathrm{Cl}(-)$-DIOP induced asymmetry in the chiral addition reactions with a high chemical yield and relatively high optical yield $(10-32 \%$ ee $)$ between $\mathrm{CCl}_{3} \mathrm{Br}$ and the vinyl monomers, no tacticity control was achieved in the polymerizations. This is probably due to the fact that the ruthenium catalyst diffuses away from the growing radical species after the abstraction of the halogen and cannot control the stereochemistry of the addition reaction between the radical species and monomer, although the stereochemistry of the capping reaction with the abstracted halogen on the ruthenium(III) species can be controlled. Thus, the lack of dependence of the tacticity on the metal catalysts suggested that the radical species in the living radical polymerization is most probably a free radical. Other methods for controlling the stereochemistry are required and must be combined with living radical polymerizations to attain the simultaneous control of the molecular weight and tacticity.

Approximately 10 years ago, Okamoto, Nakano, Habaue and coworkers found that stereospecific radical polymerization of the common polar vinyl monomers like methacrylates, vinyl ester, acrylamides and methacrylamides could be achieved using bulky fluoroalcohols as solvents or Lewis acids as additives (see Figure 3). ${ }^{39}$ In the former case, the bulky and protic fluoroalcohols such as $\left(\mathrm{CF}_{3}\right)_{3} \mathrm{COH}$ and $\left(\mathrm{CF}_{3}\right)_{2} \mathrm{CHOH}$ coordinate to the pendent carbonyl groups of the monomers and/or the growing chain ends via a hydrogen-bonding interaction due to the strong electron-withdrawing trifluoromethyl groups in the alcohols. ${ }^{111,112}$ Such bulky coordinated molecules induce steric repulsion around the growing polymer terminals to enhance conformation for the racemo addition and lead to the syndiospecific propagation of MMA and VAc. In contrast, in the latter case, the metal triflate coordinates to the carbonyl groups of not only the monomers but also the growing chain ends. ${ }^{113,114}$ In particular, multisite coordination of the Lewis acid around the growing terminals favors conformation for the meso addition to induce isospecific radical polymerizations of the acrylamide derivatives. Using these approaches, a syndiospecific or isospecific propagation was accomplished even for radical polymerization of the common vinyl polar monomers.

Along with the developments in controlling the molecular weights by living radical polymerizations and stereochemistry by a stereospecific radical polymerization, the simultaneous control of both factors were realized by the judicious combination of the two controlled radical polymerizations, in which both controlling systems should be properly selected so that the controlling components do not disturb each other. ${ }^{38,40-42}$ As for the metal-catalyzed living radical polymerization, we first examined the combination of the dinuclear iron(I) complex $\left[\mathrm{Fe}_{2} \mathrm{Cp}_{2}(\mathrm{CO})_{4}\right]$ and lanthanide triflate (for example, $\mathrm{Y}(\mathrm{OTf})_{3}$ and $\left.\mathrm{Yb}(\mathrm{OTf})_{3}\right)$ to control the molecular weight and the tacticity, respectively, in the radical polymerization of acrylamide derivatives (Figure 15). ${ }^{115}$ The low oxidation state iron(I) complex, which is one of the most active and versatile metal catalysts, induced an efficient and rather faster polymerization of $N, N$-dimethylacryla-

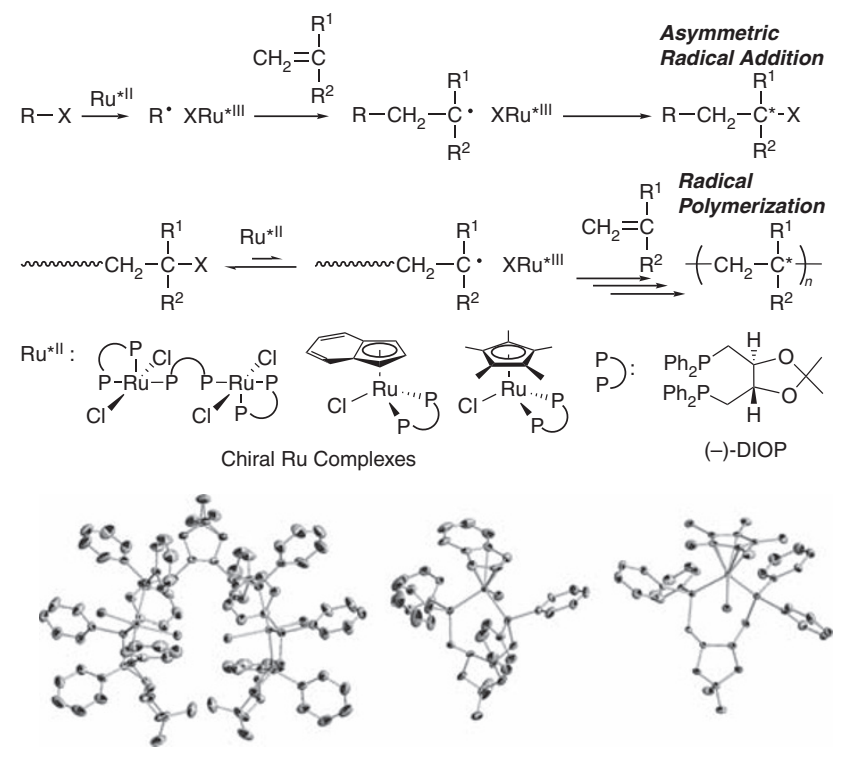

Figure 14 Chiral ruthenium-catalyzed asymmetric radical addition, living radical polymerization and ORTEP diagrams of the chiral ruthenium complexes. DIOP, 2,3-(isopropylienedioxy)-2,3-dihydroxy-1,4-bis(diphenylphosphanyl)butane; ORTEP, Oak Ridge Thermal-Ellipsoid Plot.

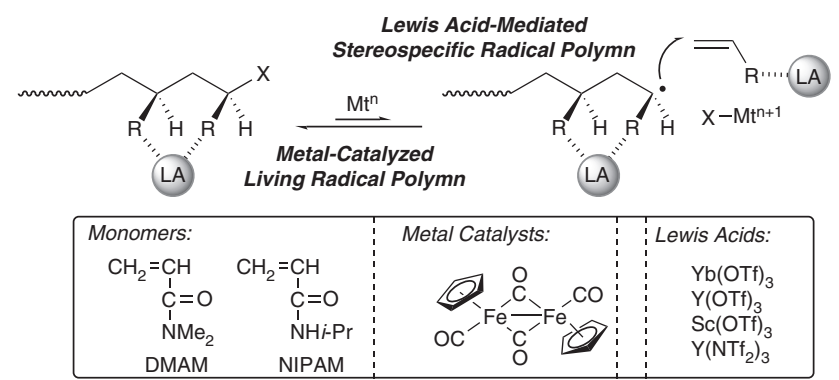

Figure 15 Stereospecific living radical polymerization of acrylamide derivatives by iron(I) complexes in the presence of lanthanide triflates; DAAM, N,Ndimethylacrylamide; NIPAM, $N$-isopropylacrylamide.

mide (DMAM) in the presence of $\mathrm{Y}(\mathrm{OTf})_{3}$ than in its absence. The polymers obtained had controlled molecular weights, whereas the MWDs were broader than those in its absence. The faster polymerization was due to an increase in the propagation rate by coordination of the added Lewis acid to the growing chain end or the monomer, whereas the broader MWDs could also be attributed to the increase in the propagation rate when compared with the interconversion between the dormant and growing radical species. The isotactic content of the obtained polymers was higher than that in the absence of $\mathrm{Y}(\mathrm{OTf})_{3}$ and almost the same as that obtained with lanthanide triflate in the absence of the iron(I) complex. Thus, neither component lost its activity or controllability, and both were successfully employed for stereospecific living radical polymerizations of DMAM.

This success further led to the synthesis of stereoblock polymers, the isotacticity of which changes abruptly at certain positions in the polymer backbone. Such unique well-defined polymers can easily be obtained by the addition of $\mathrm{Y}(\mathrm{OTf})_{3}$ into the $\mathrm{Fe}_{2} \mathrm{Cp}_{2}(\mathrm{CO})_{4}$-catalyzed living radical polymerization of DMAM, where the atactic chaingrowth suddenly changes into the isospecific one to give the atacticisotactic stereoblock poly(DMAM) (Figure 16). The copper-based ATRP was also examined by Matyjaszewski, Lutz and co-workers via 


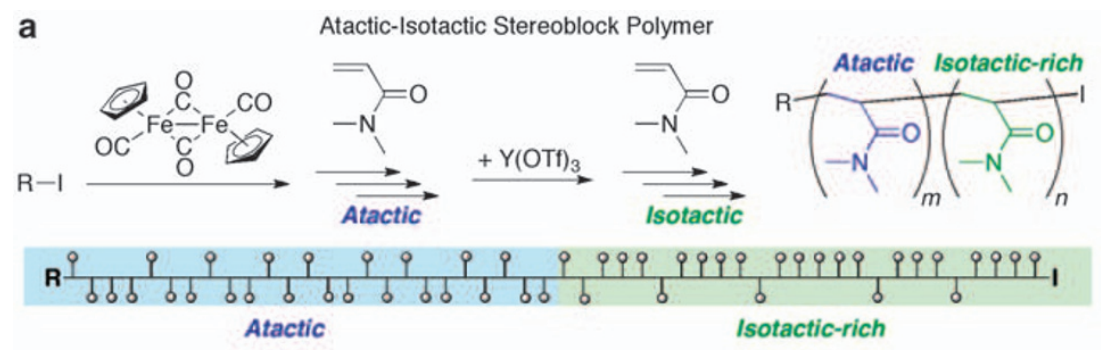

b

Syndiotactic-Atactic Stereoblock Polymer
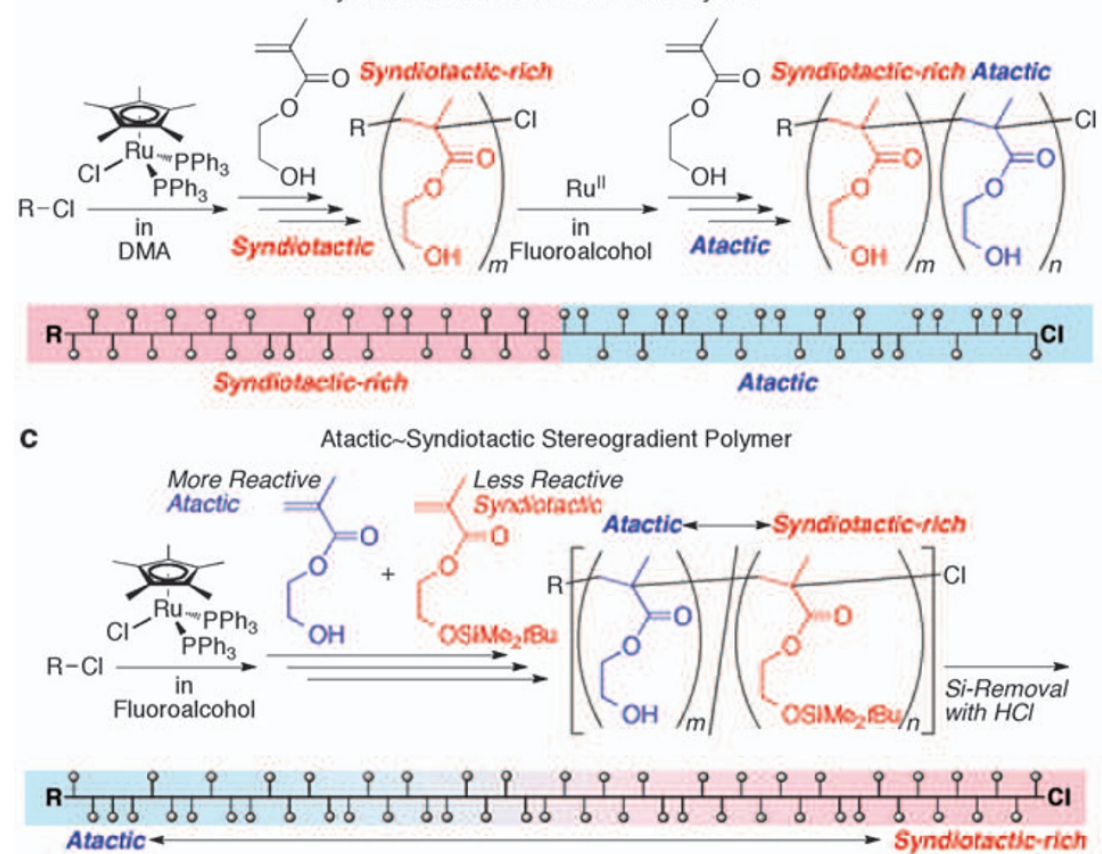

Figure 16 Atactic-isotactic stereoblock polymers of $\mathrm{N}, \mathrm{N}$-dimethylacrylamide (a), syndiotactic-atactic stereoblock polymers of 2-hydroxyethyl methacrylate (b) and atactic-syndiotactic stereogradient polymers 2-hydroxyethyl methacrylate (c). DMA, dimethylacetamide.

a combination with metal triflates for similar dual control in the radical polymerization of DMAM and stereoblock polymers, though some activity loss of the copper catalyst caused by the lanthanide triflate was observed. ${ }^{116}$ Thus, the choice of the metal catalyst is crucial for the control of the molecular weight in the presence of a Lewis acid.

Another stereospecific living radical polymerization based on metal-catalyzed living radical polymerization is the combination of ruthenium-catalyzed living radical polymerization and polar solventmediated stereospecific radical polymerization (Figure 17). ${ }^{117}$ Among the various metal catalysts, ruthenium is one of the least oxophilic metals, which suggests that ruthenium complexes might be stable enough to work as active catalysts for living radical polymerizations even in a fluoroalcohol. ${ }^{118}$ Indeed, $\mathrm{Ru}\left(\mathrm{Cp}^{*}\right) \mathrm{Cl}\left(\mathrm{PPh}_{3}\right)_{2}$ induced a faster polymerization of MMA in $\mathrm{PhC}\left(\mathrm{CF}_{3}\right)_{2} \mathrm{OH}$ than in toluene to result in polymers with controlled molecular weights and narrow MWDs $\left(M_{\mathrm{w}} /\right.$ $\left.M_{\mathrm{n}} \sim 1.1\right)$ at $0{ }^{\circ} \mathrm{C}$. The syndiotacticity was relatively high $(r r \sim 80 \%)$, which is similar to that obtained in fluoroalcohols using free radical initiators. However, the molecular weight control was affected by the types of the fluoroalcohol solvents. In $\left(\mathrm{CF}_{3}\right)_{3} \mathrm{COH}$, the polymerization with the ruthenium-Cp ${ }^{*}$ catalyst at $60^{\circ} \mathrm{C}$ was not quantitative enough to give low-molecular weight oligomers, whereas $m-\mathrm{Ph}\left[\mathrm{C}\left(\mathrm{CF}_{3}\right)_{2} \mathrm{OH}\right]_{2}$ resulted in broadening of the MWDs at $0{ }^{\circ} \mathrm{C}$. In contrast, $\mathrm{Ru}$ (Ind) $\mathrm{Cl}\left(\mathrm{PPh}_{3}\right)_{2}$ induced a fast and quantitative living radical

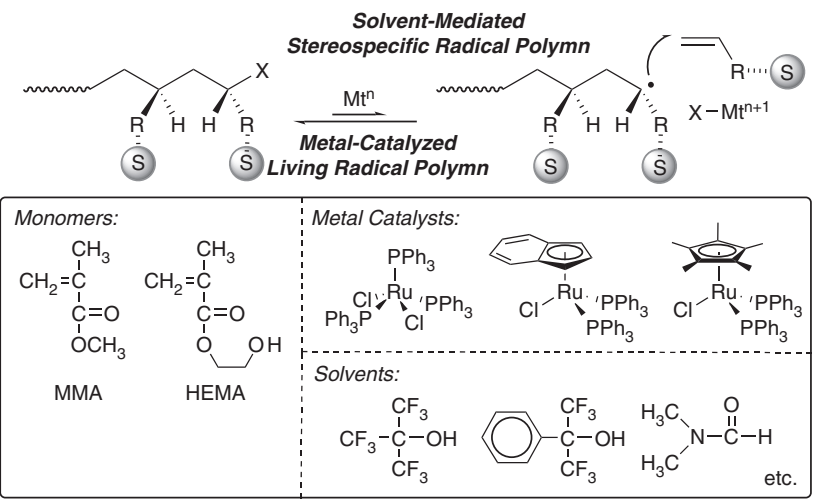

Figure 17 Stereospecific living radical polymerization of methyl and 2-hydroxyethyl methacrylate by ruthenium(II) complexes in various solvents. HEMA, 2-hydroxylethyl methacrylate; MMA, methyl methacrylate.

polymerization in $\left(\mathrm{CF}_{3}\right)_{3} \mathrm{COH}$ even at $60^{\circ} \mathrm{C}$. Kakuchi and co-workers ${ }^{119,120}$ also reported that the choice of the ligand, additives and conditions is important for achieving the $\mathrm{Cu}(\mathrm{I})$-catalyzed ATRP of MMA in $\left(\mathrm{CF}_{3}\right)_{2} \mathrm{CHOH}$. These results indicated that the appropriate combination of the metal catalyst and fluoroalcohol is crucial for the 
simultaneous control of the molecular weight and tacticity of the resulting PMMA.

For a hydroxyl-functionalized monomer, 2-hydroxylethyl methacrylate (HEMA), different dependences of the tacticity on the solvents were observed. ${ }^{117}$ Whereas bulky fluoroalcohols resulted in a decreased syndiotacticity $(r r \sim 50 \%)$ for this monomer, aprotic solvents, such as dimethylformamide (DMF) and dimethylacetamide (DMA), gave syndiotactic rich polymers $(r r \sim 80 \%)$. This can be attributed to the pendent hydroxyl groups of the HEMA units, which induced specific hydrogen-bonding interactions as indicated by the ${ }^{1} \mathrm{H}$ nuclear magnetic resonance spectroscopy analysis of the mixtures of HEMA and the solvents. Another important finding is that the ruthenium-C $\mathrm{Cp}^{\star}$ catalyst also proved effective for living radical polymerization of HEMA in various solvents, such as $\mathrm{PhC}\left(\mathrm{CF}_{3}\right)_{2} \mathrm{OH}$, DMF, DMA and $\mathrm{MeOH}$, and to give polymers with controlled molecular weights and various tacticities depending on the solvents. This system can also be applicable for the synthesis of stereoblock polymers by changing the solvents during the successive living radical polymerizations. Thus, the $\mathrm{Ru}\left(\mathrm{Cp}^{*}\right) \mathrm{Cl}\left(\mathrm{PPh}_{3}\right)_{2}$-catalyzed living radical polymerization of HEMA was first conducted in DMF to generate the syndiotactic-rich poly(HEMA) with the dormant C-Cl terminal, which was isolated by precipitation and used as a macroinitiator for the second living radical polymerization of HEMA in $\mathrm{PhC}\left(\mathrm{CF}_{3}\right)_{2} \mathrm{OH}$ to give the syndiotactic-atactic stereoblock poly(HEMA) (Figure 16).

Another novel well-defined polymer structure with a controlled molecular weight and controlled stereochemistry is a stereogradient polymer, in which the tacticity gradually changes along the polymer backbone. ${ }^{121,122}$ For the well-defined synthesis of such specific structures, we proposed a strategy based on living radical copolymerization of two monomers with different reactivities and different stereospecificities (Figure 16). ${ }^{121}$ HEMA and silyloxy-protected HEMA (SiHEMA) were chosen as the pair of monomers. The former has a slightly higher reactivity than the latter, whereas the latter give a higher syndiotacticity in a fluoroalcohol in a way similar to MMA, which has no $\mathrm{OH}$-pendent groups. Both monomers were polymerized with $\mathrm{Ru}\left(\mathrm{Cp}^{*}\right) \mathrm{Cl}\left(\mathrm{PPh}_{3}\right)_{2}$ in $\mathrm{PhC}\left(\mathrm{CF}_{3}\right)_{2} \mathrm{OH}$, in which the former was consumed about two times faster, to result in copolymers with controlled molecular weights and narrow MWDs $\left(M_{\mathrm{w}} / M_{\mathrm{n}} \sim 1.2\right)$. As the polymerization proceeded, the $M_{\mathrm{n}}$ values increased linearly, and the content of a less reactive monomer, SiHEMA, gradually increased, indicating the formation of gradient copolymers of HEMA and SiHEMA. Along with the gradual increase in the SiHEMA content in the backbone, the syndiotacticity became similarly higher. Subsequent hydrolysis of the silyl groups led to the stereogradient homopoly(HEMA), in which the syndiotacticity gradually increased.

Qiao and we further applied the ruthenium-catalyzed stereospecific living radical polymerization for preparing star polymers with syndiotactic rich PMMA arms. ${ }^{123}$ The syndiospecific living radical polymerization of MMA was first carried out with $\mathrm{Ru}\left(\mathrm{Cp}^{*}\right) \mathrm{Cl}\left(\mathrm{PPh}_{3}\right)_{2}$ in $\mathrm{PhC}\left(\mathrm{CF}_{3}\right)_{2} \mathrm{OH}$ to give the syndiotactic-rich PMMA with the dormant $\mathrm{C}-\mathrm{Cl}$ terminals. The isolated linear PMMA chain was then linked together by $\mathrm{Ru}(\mathrm{Ind}) \mathrm{Cl}\left(\mathrm{PPh}_{3}\right)_{2}$ in the presence of ethylene glycol dimethacrylate to result in star polymers with syndiotactic PMMA arms in a high yield $>95 \%$. The polymers obtained had high and controlled molecular weights $\left(M_{\mathrm{n}}=218000 ; M_{\mathrm{w}} / M_{\mathrm{n}}=1.56\right)$ and globular structures as indicated by the dynamic light scattering and transmission electron microscopy analyses $\left(D_{\mathrm{h}}\right.$ (hydrodynamic diameter $)=15 \mathrm{~nm} ; D_{\mathrm{S}}$ (solid state diameter of the object cast from the dilute solution $)=23 \mathrm{~nm}$ ). Upon the addition of the separately prepared isotactic linear PMMA chains to the solution of the syndiotactic
PMMA arm star polymers, the size of the objects became larger via the formation of stereocomplex polymer assemblies.

\section{CONCLUSION}

This review has described recent developments in metal-catalyzed living radical polymerization, specifically focusing on our studies. Since its discovery in 1994, metal-catalyzed living radical polymerization or ATRP has been widely developed in terms of many aspects, such as the catalytic systems, controllable monomers, various welldefined polymer architectures and applications to hybrid materials by combinations with various objects. The developments in the catalytic systems enabled the precise synthesis of a wide variety of well-defined polymer structures from various monomers, where the control has become close to or nearly comparable to that of living ionic polymerizations. Although it is still inferior to the living anionic polymerization in terms of perfection, it has spread to many research areas because of its wide applicability, accessibility of the reagents, easy handling and robustness to impurities besides oxygen. The developing research areas include any subjects associated with polymers, such as organic, inorganic, physical, material, medicinal, medical and industrial chemistries.

Despite extensive development, there are still unresolved problems for metal-catalyzed living radical polymerization. From the viewpoint of the catalytic systems, more active and versatile systems should be constructed, especially for application to the industrial production of the well-defined polymers, which will further enable more efficient syntheses of various well-defined polymers for novel polymeric functional materials. In addition to the control of the molecular weight, more precise control in terms of the stereochemistry and monomer sequence is another goal for radical polymerizations.

\section{ACKNOWLEDGEMENTS}

Our research goals have been achieved because of the extensive efforts of all coworkers, whom we gratefully acknowledge. We express our sincere thanks to Professor Emeritus T Higashimura and Professor M Sawamoto at Kyoto University, Distinguished invited University Professor Y Okamoto, Professor H Nishiyama and Professor E Yashima at Nagoya University, Professor J Kumaki at Yamagata University, Professor H Jinnai at the Kyoto Institute of Technology and Professor GG Qiao at the University of Melbourne for helpful suggestions, discussions and collaborations. Financial support through a Grant-in-Aid for Young Scientists (S) (No. 19675003) from the Japan Society of Promotion of Science (JSPS) is greatly appreciated.

1 Kato, M., Kamigaito, M., Sawamoto, M. \& Higashimura, T. Polymerization of methyl methacrylate with the carbon tetrachloride/dichlorotris(triphenylphosphine)- rutheniu$\mathrm{m}(\mathrm{II}) /$ methylaluminum bis(2,6-di-tert-butylphenoxide) initiating system: possibility of living radical polymerization. Macromolecules 28, 1721-1723 (1995).

2 Wang, J.- S. \& Matyjaszewski, K. Controlled/'living' radical polymerization. Atom transfer radical polymerization in the presence of transition-metal complexes. J. Am. Chem. Soc. 117, 5614-5615 (1995).

3 Percec, V. \& Barboiu, B. 'Living' radical polymerization of styrene initiated by arenesulfonyl chlorides and $\mathrm{Cu}^{\prime}(\mathrm{bpy})_{\mathrm{n}} \mathrm{Cl}$. Macromolecules 28, 7970-7972 (1995).

4 Haddleton, D. M., Jasieczek, C. B., Hannon, M. J. \& Shooter, A. J. Atom transfer radical polymerization of methyl methacrylate initiated by alkyl bromide and 2-pyridinecarbaldehyde imine copper(I) complexes. Macromolecules 30, 2190-2193 (1997).

5 Granel, C., Dubois, Ph., Jérôme, R. \& Teyssié, Ph. Controlled radical polymerization of methacrylic monomers in the presence of a bis(ortho-chelated) arylnickel(II) complex and different activated alkyl halides. Macromolecules 29, 8576-8582 (1996).

6 Sawamoto, M. \& Kamigaito, M. Metal complex-mediated living radical polymerization: features, scope, and precision polymer synthesis. J. Macromol. Sci., Pure Appl. Chem. A34, 1803-1814 (1997).

7 Sawamoto, M. \& Kamigaito, M. Transition-metal-catalyzed living radical polymerization. CHEMTECH 29, 30-38 (1999). 
8 Kamigaito, M., Ando, T. \& Sawamoto, M. Metal-catalyzed living radical polymerization. Chem. Rev. 101, 3689-3745 (2001).

9 Kamigaito, M., Ando, T. \& Sawamoto, M. Metal-catalyzed living radical polymerization: discovery and developments. Chem. Rec. 4, 159-175 (2004).

10 Ouchi, M., Terashima, T. \& Sawamoto, M. Precision control of radical polymerization via transition metal catalysis: from dormant species to designed catalysts for precision functional polymers. Acc. Chem. Res. 41, 1120-1132 (2008).

11 Ouchi, M., Terashima, T. \& Sawamoto, M. Transition metal-catalyzed living radical polymerization: toward perfection in catalysis and precision polymer synthesis. Chem. Rev. 109, 4963-5050 (2009).

12 Matyjaszewski, K. \& Xia, J. Atom transfer radical polymerization. Chem. Rev. 101, 2921-2990 (2001)

13 Tsarevsky, N. V. \& Matyjaszewski, K. ‘Green' atom transfer radical polymerization: from process design to preparation of well-defined environmentally friendly polymeric material. Chem. Rev. 107, 2270-2299 (2007).

14 Braunecker, W. A. \& Matyjaszewski, K. Controlled/living radical polymerization: features, developments, and perspectives. Prog. Polym. Sci. 32, 93-146 (2007).

15 Matyjaszewski, K. \& Tsarevsky, N. V. Nanostructured functional materials prepared by atom transfer radical polymerization. Nat. Chem. 1, 276-288 (2009).

16 di Lena, F. \& Matyjaszewski, K. Transition metal catalysts for controlled radical polymerization. Prog. Polym. Sci. 35, 959-1021 (2010).

17 Rosen, B. M. \& Percec, V. Single-electron transfer and single-electron transfer degenerative chain transfer living radical polymerization. Chem. Rev. 109, 50695119 (2009).

18 Hawker, C. J., Bosman, A. W. \& Harth, E. New polymer synthesis by nitroxide mediated living radical polymerization. Chem. Rev. 101, 3661-3688 (2001).

19 Studer, A. \& Shulte, T. Nitroxide-mediated radical processes. Chem. Rec. 5, 27-35 (2005).

20 Sciannamea, V., Jérôme, R. \& Detrembleur, C. In-situ nitroxide-mediated radical polymerization (NMP) process: their understanding and optimization. Chem. Rev. 108, 1104-1126 (2008).

21 Moad, G., Rizzardo, E. \& Thang, S. H. Living radical polymerization by the RAFT process. Aust. J. Chem. 58, 379-410 (2005)

22 Moad, G., Rizzardo, E. \& Thang, S. H. Living radical polymerization by the RAFT process-a first update. Aust. J. Chem. 59, 669-692 (2006).

23 Moad, G., Rizzardo, E. \& Thang, S. H. Living radical polymerization by the RAFT process-a second update. Aust. J. Chem. 62, 1402-1472 (2009).

24 Fischer, $\mathrm{H}$. The persistent radical effect: a principle for selective radical reactions and living radical polymerization. Chem. Rev. 101, 3661-3688 (2001).

25 David, G., Boyer, C., Tonnar, J., Ameduri, B., Lacroix-Desmazes, P. \& Boutevin, B. Use of iodocompounds in radical polymerization. Chem. Rev. 106, 3936-3962 (2006).

26 Wayland, B. B., Poszmik, G., Mukerjee, S. L. \& Fryd, M. Living radical polymerization of acrylates by organocobalt porphyrin complexes. J. Am. Chem. Soc. 116, 79437944 (1994).

27 Asandei, A. D. \& Moran, I. W. TiCp 2 Cl-catalyzed living radical polymerization of styrene initiated by oxirane radical ring opening. J. Am. Chem. Soc. 126, 1593215933 (2004).

28 Poli, R. Relationship between one-electron transfer-metal reactivity and radical polymerization process. Angew. Chem. Int. Ed. 45, 5058-5070 (2006).

29 Goto, A. \& Fukuda, T. Kinetics of living radical polymerization. Prog. Polym. Sci. 29, 329-385 (2004).

30 Zetterlund, P. B., Kagawa, Y. \& Ohkubo, M. Controlled/living radical polymerization in dispersed systems. Chem. Rev. 108, 3747-3794 (2008).

31 Yamago, S. Precision polymer synthesis by degenerative transfer controlled/living radical polymerization using organotellurium, organostibine, and organobismuthine chain-transfer agents. Chem. Rev. 109, 5051-5068 (2009).

32 Boyer, C., Bulmus, V., Davis, T. P., Ladmiral, V., Liu, J. \& Periier, S. Bioapplications of RAFT polymerization. Chem. Rev. 109, 5402-5436 (2009).

33 Barbey, R., Lavanant, L., Paripoic, D., Scüher, N., Sugnaux, C., Tugulu, S. \& Klok, H.A. Polymer brushes via surface-initiated controlled radical polymerization: synthesis, characterization, properties, and applications. Chem. Rev. 109, 5402-5436 (2009).

34 Moad, G. \& Solomon, D. H. The Chemistry of Radical Polymerization, second fully revised edition (Elsevier Science, Oxford, 2006).

35 Kharasch, M. S., Jensen, E. V. \& Urry, W. H. Addition of carbon tetrachloride and chloroform to olefins. Science 102, 128 (1945).

36 Sawamoto, M. Modern cationic vinyl polymerization. Prog. Polym. Sci. 16, 111-172 (1991).

37 Aoshima, S. \& Kanaoka, S. A renaissance in living cationic polymerization. Chem. Rev. 109, 5142-5287 (2009).

38 Satoh, K. \& Kamigaito, M. Stereospecific living radical polymerization: dual control of molecular weight and tacticity for precision polymer synthesis. Chem. Rev. 109, 5120-5156 (2009).

39 Habaue, S. \& Okamoto, Y. Stereocontrol in radical polymerization. Chem. Rec. 1, 46-52 (2001).

40 Kamigaito, M., Satoh, K., Wan, D., Sugiyama, Y., Koumura, K., Shibata, T. \& Okamoto, Y. Stereospecific living radical polymerization. ACS Symp. Ser. 944, 26-39 (2006).

41 Kamigaito, M. \& Satoh, K. Stereospecific living radical polymerization for simultaneous control of molecular weight and tacticity. J. Polym. Sci. Part A Polym. Chem. 44, 6147-6158 (2006).

42 Kamigaito, M. \& Satoh, K. Stereoregulation in living radical polymerization. Macromolecules 41, 269-276 (2008).

43 Takahashi, H., Ando, T., Kamigaito, M. \& Sawamoto, M. Half-metallocene-type ruthenium complexes as active catalysts for living radical polymerization of methyl methacrylate and styrene. Macromolecules 32, 3820-3823 (1999).
44 Watanabe, Y., Ando, T., Kamigaito, M. \& Sawamoto, M. Ru(Cp*)Cl(PPh $)_{2}$ : a versatile catalyst for living radical polymerization of methacrylate, acrylate, and styrene. Macromolecules 34, 4370-4374 (2001).

45 Kamigaito, M., Watanabe, Y., Ando, T. \& Sawamoto, M. A new ruthenium complex with an electron-donating aminoindenyl ligand for fast metal-mediated living radical polymerizations. J. Am. Chem. Soc. 124, 9994-9995 (2002).

46 Ando, T., Kamigaito, M. \& Sawamoto, M. Catalytic activities of ruthenium(II) complexes in transition metal-mediated living radical polymerization: polymerization, model reaction, and cyclic voltammetry. Macromolecules 33, 5825-5829 (2000).

47 Simal, F., Wlodarczak, L., Demonceau, A. \& Noels, A. F. Highly efficient Kharasch addition catalysed by $\mathrm{Ru}\left(\mathrm{Cp}^{*}\right) \mathrm{Cl}\left(\mathrm{PPh}_{3}\right)_{2}$. Tetrahedron Lett. 41, 6071-6074 (2000).

48 Quebatte, L., Thommes, K. \& Severin, K. Highly efficient atom transfer radical addition reactions with a Rulll complex as a catalyst precursor. J. Am. Chem. Soc. 128, 7440-7441 (2006).

49 Ando, T., Kamigaito, M. \& Sawamoto, M. Metal alkoxides as additives for rutheniu$\mathrm{m}(\mathrm{II})$-mediated living radical polymerization. Macromolecules 33, 6732-6737 (2000).

50 Hamasaki, S., Kamigaito, M. \& Sawamoto, M. Amine-additives for fast living radical polymerization of methyl methacrylate with $\mathrm{RuCl}_{2}\left(\mathrm{PPh}_{3}\right)_{3}$. Macromolecules 35, 2934-2940 (2002).

51 Hamasaki, S., Sawauchi, C., Kamigaito, M. \& Sawamoto, M. Ruthenium-catalyzed fast living radical polymerization of methyl methacrylate: the $\mathrm{R}-\mathrm{Cl} / \mathrm{Ru}(\mathrm{Ind}) \mathrm{Cl}\left(\mathrm{PPh}_{3}\right)_{2}$ / $n$ - $\mathrm{Bu}_{2} \mathrm{NH}$ initiating system 40, 617-623 (2002).

52 Ando, T., Sawauchi, C., Ouchi, M., Kamigaito, M. \& Sawamoto, M. Amino alcohol additives for the fast living radical polymerization of methyl methacrylate with $\mathrm{RuCl}_{2}\left(\mathrm{PPh}_{3}\right)_{3}$. J. Polym. Sci. Part A Polym. Chem. 41, 3597-3605 (2003)

53 Kamigaito, M., Ando, T. \& Sawamoto, M. Living radical polymerization with designed metal complexes. ACS Symp. Ser. 854, 102-115 (2003).

54 Fukuzaki, Y., Tomita, Y., Terashima, T., Ouchi, M. \& Sawamoto, M. Bisphosphine monoxide-ligated ruthenium catalysts: active, versatile, removable, and cocatalystfree in living radical polymerization. Macromolecules 43, 5989-5995 (2010).

55 Ando, T., Kamigaito, M. \& Sawamoto, M. Iron(II) chloride complex for living radical polymerization of methyl methacrylate. Macromolecules 30, 4507-4510 (1997).

56 Kotani, Y., Kamigaito, M. \& Sawamoto, M. $\mathrm{FeCp}(\mathrm{CO})_{2} \mathrm{l}$ : a phosphine-free halfmetallocene-type iron(II) catalyst for living radical polymerization of styrene. Macromolecules 32, 6877-6880 (1999).

57 Kotani, Y., Kamigaito, M. \& Sawamoto, M. Living radical polymerization of styrene by half-metallocene iron carbonyl complexes. Macromolecules 33, 3543-3549 (2000).

58 Onishi, I., Baek, K.- Y., Kotani, Y., Kamigaito, M. \& Sawamoto, M. Iron-catalyzed living radical polymerization of acrylates: iodide-based initiating systems and block and random copolymerizations. J. Polym. Sci. Part A Polym. Chem. 40, 2033-2043 (2002).

59 Kamigaito, M., Onishi, I., Kimura, S., Kotani, Y. \& Sawamoto, M. A highly active Fe(I) catalyst for radical polymerisation and taming the polymerisation with iodine. Chem. Commun. 2694-2695 (2002).

60 Wakioka, M., Baek, K.- Y., Ando, T., Kamigaito, M. \& Sawamoto, M. Possibility of living radical polymerization of vinyl acetate catalyzed by iron(I) complex. Macromolecules 35, 330-333 (2002).

61 Percec, V., Barboiu, B. \& van der Sluis, M. Self-regulated phase transfer of $\mathrm{Cu}_{2} \mathrm{O} / \mathrm{bpy}$, $\mathrm{Cu}(0) / \mathrm{bpy}$, and $\mathrm{Cu}_{2} \mathrm{O} / \mathrm{Cu}(0) / \mathrm{bpy}$ catalyzed 'living' radical polymerization initiated with sufonyl chlorides. Macromolecules 31, 4053-4056 (1998).

62 Percec, V., Popov, A. V., Ramirez-Castillo, E., Monteiro, M., Barboiu, B., Weichold, O., Asandei, A. D. \& Mitchell, C. M. Aqueous room temperature metal-catalyzed living radical polymerization of vinyl chloride. J. Am. Chem. Soc. 124, 4940-4941 (2002).

63 Percec, V., Guliashvili, T., Ladislaw, J. S., Wistrand, A., Stjerndahl, A., Sienkowska, M. J., Monteiro, M. J. \& Sahoo, S. Ultrafast synthesis of ultrahigh molar mass polymers by metal-catalyzed living radical polymerization of acrylates, methacrylates, and vinyl chloride mediated by SET at $25^{\circ} \mathrm{C}$. J. Am. Chem. Soc. 128, 14156-14165 (2006).

64 Lligadas, G., Rosen, B. M., Monteiro, M. J. \& Percec, V. Solvent choice differentiates SET-LRP and Cu-mediated radical polymerization with non-first-order kinetics. Macromolecules 41, 8360-8364 (2008).

65 Lligadas, G., Rosen, B. M., Bell, C. A., Monteiro, M. J. \& Percec, V. Effect of Cu(0) particle size on the kinetics of SET-LRP in DMSO and Cu-mediated radical polymerization in MeCN at $25{ }^{\circ} \mathrm{C}$. Macromolecules 41, 8365-8371 (2008).

66 Nguyen, N. H., Rosen, B. M., Lligadas, G. \& Percec, V. Surface-dependent kinetics of $\mathrm{Cu}(0)$-wire-catalyzed single-electron transfer living radical polymerization of methyl acrylate in DMSO at $25^{\circ} \mathrm{C}$. Macromolecules 42, 2379-2386 (2009).

67 Jakubowski, W., Min, K. \& Matyjaszewski, K. Activators regenerated by electron transfer for atom transfer radical polymerization of styrene. Macromolecules $\mathbf{3 9}$, 39-45 (2006).

68 Jakubowski, W. \& Matyjaszewski, K. Activators regenerated by electron transfer for atom-transfer radical polymerization of (meth)acrylates and related block copolymers. Angew. Chem. Int. Ed. 45, 4482-4486 (2006).

69 Matyjaszewski, K., Jakubowski, W., Min, K., Tang, W., Huang, J., Braunecker, W. A. \& Tsarevsky, N. V. Diminishing catalyst concentration in atom transfer radical polymerization with reducing agents. Proc. Natl Acad. Sci. USA 103, 15309-15314 (2006).

70 Matyjaszewski, K., Tsarevsky, N. V., Braunecker, W. A., Dong, H., Huang, J., Jakubowski, W., Kwak, Y., Nicolay, R., Tang, W. \& Yoon, J. A. Role of $\mathrm{Cu}^{0}$ in controlled/ ‘living' radical polymerization. Macromolecules 40, 7795-7806 (2007).

71 Koumura, K., Satoh, K. \& Kamigaito, M. Manganese-based controlled/living radical polymerization of vinyl acetate, methyl acrylate, and styrene: highly active, versatile, and photoresponsive systems. Macromolecules 41, 7359-7367 (2008). 
72 Koumura, K., Satoh, K. \& Kamigaito, M. $\mathrm{Mn}_{2}(\mathrm{CO})_{10}$-induced controlled/living radical copolymerization of vinyl acetate and methyl acrylate: spontaneous formation of block copolymers consisting of gradient and homopolymer segments. J. Polym. Sci. Part A Polym. Chem. 47, 1343-1353 (2009).

73 Koumura, K., Satoh, K. \& Kamigaito, M. $\mathrm{Mn}_{2}(\mathrm{CO})_{10}$-induced controlled/living radical copolymerization of methyl acrylate and 1-hexene in fluoroalcohol: high $\alpha$-olefin content copolymers with controlled molecular weights. Macromolecules 42 2497-2504 (2009)

74 Koumura, K., Satoh, K. \& Kamigaito, M. $\mathrm{Mn}_{2}(\mathrm{CO})_{10}$-induced RAFT polymerization of vinyl acetate, methyl acrylate, and styrene. Polym. J. 41, 595-603 (2009).

75 Uciike, C., Terashima, T., Ouchi, M., Ando, T., Kamigaito, M. \& Sawamoto, M. Evolution of iron catalysts for effective living radical polymerization: design of phosphine/halogen ligands in $\mathrm{FeX}_{2}\left(\mathrm{PR}_{3}\right)_{2}$. Macromolecules 40, 8658-8662 (2007).

76 Uciike, C., Terashima, T., Ouchi, M., Ando, T., Kamigaito, M. \& Sawamoto, M. Evolution of iron catalysts for effective living radical polymerization: $\mathrm{P}-\mathrm{N}$ chelate ligand for enhancement of catalytic performances. J. Polym. Sci. Part A Polym. Chem. 46, 6819-6827 (2008)

77 Niibayashi, S., Hayakawa, H., Jin, R.- H. \& Nagashima, H. Reusable and environmentally friendly ionic trinuclear iron complex catalyst for atom transfer radical polymerization. Chem. Commun. 1855-1857 (2007).

78 Kawamura, M., Sunada, Y., Kai, H., Koike, N., Hamada, A., Hayakawa, H., Jin, R.- H. \& Nagashima, H. New iron(II) complex for atom-transfer radical polymerization: the ligand design for triazacyclononane results in high reactivity and catalyst performance. Adv. Synth. Catal. 351, 2086-2090 (2009).

79 Wang, J.- S. \& Matyjaszewski, K. 'Living'/controlled radical polymerization. Transitionmetal-catalyzed atom transfer radical polymerization in the presence of a conventional radical initiator. Macromolecules 28, 7572-7573 (1995).

80 Moineau, G., Dubois, Ph., Jérôme, R., Senninger, T. \& Teyssié, Ph. Alternative atom transfer radical polymerization for MMA using $\mathrm{FeCl}_{3}$ and $\mathrm{AIBN}$ in the presence of triphenylphosphine: an easy way to well-controlled PMMA. Macromolecules 31, 545-547 (1998)

81 Luo, R. \& Sen, A. Electron-transfer-induced iron-based atom transfer radical polymerization of styrene derivatives and copolymerization of styrene and methyl methacrylate. Macromolecules 41, 4154-4158 (2008).

82 Satoh, K., Aoshima, H. \& Kamigaito, M. Iron(III) chloride/R-Cl/tributylphosphine for metal-catalyzed living radical polymerization: a unique system with a higher oxidation state iron complex. J. Polym. Sci. Part A Polym. Chem. 46, 6358-6363 (2008).

83 Xue, Z., Linh, N. T. B., Noh, S. K. \& Lyoo, W. S. Phosphorous-containing ligands for iron(III)-catalyzed atom transfer radical polymerization. Angew. Chem. Int. Ed. 47, 6426-6429 (2008).

84 Xue, Z., Oh, H. S., Noh, S. K. \& Lyoo, W. S. Phosphorous ligands for iron(III)-mediated atom transfer radical polymerization of methyl methacrylate. Macromol. Rapid Commun. 29, 1887-1894 (2008).

85 Xue, Z., He, D., Noh, S. K. \& Lyoo, W. S. Iron(III)-mediated atom transfer radical polymerization in the absence of any additives. Macromolecules 42, 2949-2957 (2009).

86 He, D., Xue, Z., Khan, M. Y., Noh, S. K. \& Lyoo, W. S. Phosphorous ligands for iron(III)mediated ATRP of styrene via generation of activators by monomer addition. J. Polym. Sci. Part A Polym. Chem. 48, 144-151 (2010).

87 Baek, K.- Y., Kamigaito, M. \& Sawamoto, M. Synthesis of end-functionalized PMMA by ruthenium-catalyzed living radical polymerization with functionalized initiators. J. Polym. Sci. Part A Polym. Chem. 40, 1937-1944 (2002).

88 Ando, T., Kamigaito, M. \& Sawamoto, M. Silyl enol ethers: end-capping agents for living radical polymerization of methyl methacrylate with ruthenium complex. Macromolecules 31, 6708-6711 (1998)

89 Tokuchi, K., Ando, T., Kamigaito, M. \& Sawamoto, M. Quenching of metal-catalyzed living radical polymerization with silyl enol ethers. J. Polym. Sci. Part A Polym. Chem. 38, 4735-4748 (2000)

90 Ueda, J., Matsuyama, M., Kamigaito, M. \& Sawamoto, M. Multifunctional initiators for the ruthenium-mediated living radical polymerization of methyl methacrylate: di- and trifunctional dichloroacetates for synthesis of multiarmed polymers. Macromolecules 31, 557-562 (1998)

91 Ueda, J., Kamigaito, M. \& Sawamoto, M. Calixarene-core multifunctional initiators for the ruthenium-mediated living radical polymerization of methacrylates. Macromolecules 31, 6762-6768 (1998)

92 Gao, H. \& Matyjaszewski, K. Synthesis of star polymers by a new 'core-first' method: sequential polymerization of cross-linker and monomer. Macromolecules 41, 11181125 (2008)

93 Baek, K.- Y., Kamigaito, M. \& Sawamoto, M. Star-shaped polymers by metal-catalyzed living radical polymerization. 1 . Design of $\mathrm{Ru}(\mathrm{II})$-based systems and divinyl linking agents. Macromolecules 34, 215-221 (2001)

94 Baek, K.- Y., Kamigaito, M. \& Sawamoto, M. Star-shaped polymers by metal-catalyzed living radical polymerization. 2. Effect of reaction conditions and characterization by MALLS/SEC and SAXS. J. Polym. Sci. Part A Polym. Chem. 40, 2245-2255 (2002)

95 Baek, K.- Y., Kamigaito, M. \& Sawamoto, M. Synthesis of star-shaped polymers with methyl methacrylate and $n$-butyl methacrylate by metal-catalyzed living radical polymerization: block- and random-copolymer arms, and microgel cores. J. Polym. Sci. Part A Polym. Chem. 40, 633-641 (2002).

96 Baek, K.- Y., Kamigaito, M. \& Sawamoto, M. Star poly(methyl methacrylate) with endfunctionalized arm chains by ruthenium-catalyzed living radical polymerization. J. Polym. Sci. Part A Polym. Chem. 40, 1972-1982 (2002).
97 Baek, K.- Y., Kamigaito, M. \& Sawamoto, M. Core-functionalized star polymers by transition metal-catalyzed living radical polymerization. 1 . Synthesis and characterization of star polymers with PMMA arms and amide cores. Macromolecules 34, 7629-7635 (2001)

98 Baek, K.- Y., Kamigaito, M. \& Sawamoto, M. Core-functionalized star polymers by transition metal-catalyzed living radical polymerization. 2. Selective interaction with protic guests via core functionalities. Macromolecules 35, 1493-1498 (2002).

99 Terashima, T., Kamigaito, M., Baek, K.- Y., Ando, T. \& Sawamoto, M. Polymer catalysts from polymerization catalysts: direct encapsulation of metal catalysts into star polymer core during metal-catalyzed living radical polymerization. J. Am. Chem. Soc. 125, 5288-5289 (2003).

100 Terashima, T., Ouchi, M., Ando, T., Kamigaito, M. \& Sawamoto, M. Metal-complexbearing star polymers by metal-catalyzed living radical polymerization: synthesis and characterization of poly(methyl methacrylate) star polymers with $\mathrm{Ru}(\mathrm{II})$-embedded microgel cores. J. Polym. Sci. Part A Polym. Chem. 44, 4966-4980 (2006).

101 Terashima, T., Ouchi, M., Ando, T., Kamigaito, M. \& Sawamoto, M. Amphiphilic, thermosensitive ruthenium(II)-bearing star polymer catalysts: one-pot synthesis of PEG armed star polymers with ruthenium(II)-enclosed microgel cores via metalcatalyzed living radical polymerization. Macromolecules 40, 3581-3588 (2007).

102 Terashima, T., Ouchi, M., Ando, T. \& Sawamoto, M. Thermoregulated phase-transfer catalysis via PEG-armed Ru(II)-bearing microgel core star polymers: efficient and reusable Ru(II) catalysts for aqueous transfer hydrogenation of ketones. J. Polym. Sci. Part A Polym. Chem. 48, 373-379 (2010).

103 Isonaga, M., Satoh, K., Kamigaito, M. \& Okamoto, Y. Star polymers with chiralfunctionalized core by living radical polymerization: synthesis and characterization. ACS Polym. Prepr. 46, 401-402 (2005).

104 Chi, Y., Scroggins, S. T. \& Fréchet, J. M. J. One-pot multi-component asymmetric cascade reactions catalyzed by soluble star polymers with highly branched noninterpenetrating catalytic cores. J. Am. Chem. Soc. 130, 6322-6323 (2008).

105 Miura, Y., Satoh, K., Kamigaito, M. \& Okamoto, Y. Well-defined graft copolymers of methacrylate, acrylate, and styrene via ruthenium-catalyzed living radical polymerization. Polym. J. 38, 930-939 (2006).

106 Miura, Y., Satoh, K., Kamigaito, M., Okamoto, Y., Kaneko, T., Jinnai, H. \& Kobukata, S. $A_{x} B A_{x}$-type block-graft polymers with middle soft segments and outer hard graft chains by ruthenium-catalyzed living radical polymerization: synthesis and characterization. Macromolecules 40, 465-473 (2007).

107 Miura, Y., Kaneko, T., Satoh, K., Kamigaito, M., Jinnai, H. \& Okamoto, Y. A B BAx-type block-graft polymers with soft methacrylate middle segments and hard styrene outer grafts: synthesis, morphology, and mechanical properties. Chem. Asian J. 2, 662-672 (2007)

108 Jinnai, H., Spontak, R. J. \& Nishi, T. Transmission electron microtomography and polymer nanostructures. Macromolecules 43, 1675-1688 (2010).

109 Kameyama, M., Kamigata, N. \& Kobayashi, M. Asymmetric radical reaction in the coordination sphere. 2. Asymmetric addition of alkane- and arenesulfonyl chlorides to olefins catalyzed by a ruthenium(II)-phosphine complex with chiral ligands. J. Org. Chem. 52, 3312-3316 (1987).

110 lizuka, Y, Li, Z Satoh, K., Kamigaito, M. Okamoto, Y, Ito, J \& Nishiyama, H Chiral (-)-DIOP ruthenium complexes for asymmetric radical addition and living radical polymerization reactions. Eur. J. Org. Chem. 782-791 (2007).

111 Yamada, K., Nakano, T. \& Okamoto, Y. Stereospecific free radical polymerization of vinyl esters using fluoroalcohols as solvents. Macromolecules 31, 7598-7605 (1998)

112 Isobe, Y., Yamada, K., Nakano, T. \& Okamoto, Y. Stereospecific free-radical polymerization of methacrylates using fluoroalcohols as solvents. Macromolecules 32, 5979-5981 (1999)

113 Isobe, Y., Fujioka, D., Habaue, S. \& Okamoto, Y. Efficient Lewis acid-catalyzed stereocontrolled radical polymerization of acrylamides. J. Am. Chem. Soc. 123, 7180-7181 (2001)

114 Isobe, Y., Nakano, T. \& Okamoto, Y. Stereocontrol during the free-radical polymerization of methacrylates with Lewis acids. J. Polym. Sci. Part A Polym. Chem. 39, 1463-1471 (2001).

115 Sugiyama, Y., Satoh, K., Kamigaito, M. \& Okamoto, Y. Iron-catalyzed radical polymerization of acrylamides in the presence of Lewis acid for simultaneous control of molecular weight and tacticity. J. Polym. Sci. Part A Polym. Chem. 44, 2086-2098 (2006).

116 Lutz, J.- F., Neugebauer, D. \& Matyjaszewski, K. Stereoblock copolymers and tacticity control in controlled/living radical polymerization. J. Am. Chem. Soc. 125, 6986-6993 (2003)

117 Shibata, T., Satoh, K., Kamigaito, M. \& Okamoto, Y. Simultaneous control of the stereospecificity and molecular weight in the ruthenium-catalyzed living radical polymerization of methyl and 2-hydroxyethyl methacrylates and sequential synthesis of stereoblock polymers. J. Polym. Sci. Part A Polym. Chem. 44, 3609-3615 (2006)

118 Nishikawa, T., Ando, T., Kamigaito, M. \& Sawamoto, M. Evidence for living radical polymerization of MMA with ruthenium complex: effects of protic compounds and reinitiation from the recovered polymers. Macromolecules 30, 2244-2248 (1997).

119 Miura, Y. Satoh, T., Narumi, A., Nishizawa, O., Okamoto, Y \& Kakuchi, T. Atom transfer radical polymerization of methyl methacrylate in fluoroalcohol: simultaneous control of molecular weight and tacticity. Macromolecules 38 , 1041-1043 (2005).

120 Miura, Y., Satoh, T., Narumi, A., Nishizawa, O., Okamoto, Y. \& Kakuchi, T. Synthesis of well-defined syndiotactic poly(methyl methacrylate) using low temperature atom 
transfer radical polymerization in fluoroalcohol. J. Polym. Sci. Part A Polym. Chem. 44, 1436-1446 (2006)

121 Miura, Y., Shibata, T., Satoh, K., Kamigaito, M. \& Okamoto, Y. Stereogradient polymers by ruthenium-catalyzed stereospecific living radical copolymerization of two monomers with different stereospecificities and reactivities. J. Am. Chem. Soc. 128, 16026-16027 (2006).
122 Ishitake, K., Satoh, K., Kamigaito, M. \& Okamoto, Y. Stereogradient polymers formed by controlled/living radical polymerization of bulky methacrylate monomers. Angew. Chem. Int. Ed. 48, 1991-1994 (2009).

123 Goh, T. K., Tan, J. F., Guntari, S. N., Satoh, K., Blencowe, A., Kamigaito, M. \& Qiao, G.G. Nano-to-macroscale poly(methyl methacrylate) stereocomplex assemblies. Angew. Chem. Int. Ed. 48, 8707-8711 (2009).

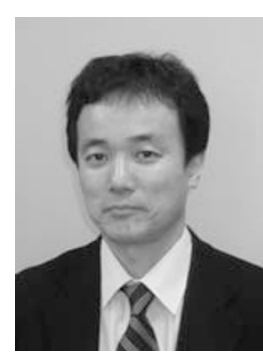

Masami Kamigaito was born in 1965 in Nagoya, Japan. He received his BS (1988), MS (1990) and PhD (1993) degrees in polymer chemistry from Kyoto University under the direction of Professor Toshinobu Higashimura. After conducting postdoctoral research with Professor Mitsuo Sawamoto, he joined the faculty of Kyoto University in 1995, where he was promoted to Associate Professor in 1999. In 2003, he moved to Nagoya University as an Associate Professor, working with Professor Yoshio Okamoto and was promoted to Professor in 2004. In 1997-1998, he was a visiting scientist at Stanford University, working with Professor Robert M Waymouth. He is the recipient of the 2001 Arthur K Doolittle Award from the ACS's PMSE Division and the 2009 Wiley Polymer Science Award from the Society of Polymer Science, Japan. His research interests include controlled radical and cationic polymerizations, the development of new polymerizations and their applications to precision polymer synthesis. 